\title{
How do taxpayers respond to a large kink? Evidence on earnings and deduction behavior from Austria
}

\author{
Joerg Paetzold $^{1}$ (D)
}

Published online: 13 April 2018

(C) The Author(s) 2018

\begin{abstract}
This paper contributes to recent literature examining the importance of the different channels through which taxable income responses occur. Using bunching techniques and exploiting a large kink point where marginal tax rates increase by as much as 38 percentage points, I first recover modest gross earnings responses of Austrian employees. Next, I demonstrate that when accounting for deduction behavior, the additional mass of wage earners at the kink increases by around 50\%. I show direct evidence of wage earners targeting the kink with their deduction claiming. Finally, I contrast the responses of wage earners with those of self-employed taxpayers, and find that access to different tax adjustment channels corresponds with different adjustment behavior. In sum, my results suggest that distinguishing between earnings and deduction responses matters even for taxpayers with only limited possibilities to shelter taxable income.
\end{abstract}

Keywords Bunching - Earnings elasticity · Tax expenditures - Deduction behavior . Administrative data

JEL Classification $\mathrm{H} 21 \cdot \mathrm{H} 24 \cdot \mathbf{J} 22$

\section{Introduction}

Following Chetty (2009), the economic analysis of taxation has put increasing emphasis on the different adjustment channels along which taxable income responses occur. For instance, it has been proposed to study (gross) earned income and taxable income

\footnotetext{
$\bowtie \quad$ Joerg Paetzold

joerg.paetzold@sbg.ac.at

1 Universitat Salzburg, Salzburg, Austria
} 
responses separately (Chetty 2009; Saez et al. 2012; Doerrenberg et al. 2016). In recent years, the literature moved toward examining such different adjustment channels, aiming to explore the mechanisms behind the responsiveness of taxpayers. This paper contributes to this literature and studies the effect of taxes on two important adjustment channels for wage earners, namely their earnings supply and deduction behavior. Previous studies have mostly found such responses to be concentrated among the self-employed (see, e.g., Bastani and Selin 2014), or did not distinguish between wage earners and self-employed taxpayers (Doerrenberg et al. 2016). However, this distinction seems important since self-employed taxpayers are much less constrained by third-party reporting when filing their taxes, which makes it difficult to separate between their (gross) earnings supply and deduction response (Saez et al. 2012). In addition, self-employed taxpayers have much easier access to extensive tax planning compared to wage earners, for instance via retained earnings, income shifting or the claiming of business expenses (Maire and Schjerning 2013; LaLumia et al. 2015; Harju and Matikka 2016). Laboratory experiments suggest that varying access to different tax adjustment channels is inter-related, with easier access to one channel affecting the use of other channels (Doerrenberg and Duncan 2014). This motivates my analysis to focus on taxpayers with third-party reported earnings only but access to a set of deduction possibilities, allowing to distinguish between the gross earnings supply and deduction response more accurately. Furthermore, I contrast the responses of wage earners with data of self-employed taxpayers and examine whether access to different adjustment channels indeed corresponds with different adjustment behavior.

My study employs an identification strategy well suited to provide evidence of the effect of taxes on deduction and earnings behavior. Specifically, I apply bunching techniques and exploit a large and salient kink point in the Austrian income tax schedule. In 2005, Austria introduced a first tax bracket where the marginal tax rate increases by as much as 38.33 percentage points. This is a substantially bigger change in marginal tax rates compared to most other tax schedules found elsewhere and thus represents a promising laboratory to study behavioral responses of taxpayers. Using this large kink for identification, I do not rely on instruments constructed from tax reforms to identify behavioral responses. This avoids the mechanical effect induced by simultaneous tax rate and tax base changes inherent in many tax reforms (Saez et al. 2012; Doerrenberg et al. 2016). ${ }^{1}$ In fact, I focus on a period with few changes in tax base definitions or reforms, which makes my results more robust to this challenge. By looking at changes in the earnings distribution over many years after a major tax reform, I also document how changes in the tax schedule can distort earnings distributions over a longer time horizon. For my study I employ high-quality administrative data comprising the universe of Austrian payslips (comparable to W-2 forms in the U.S.), which entail third-party reported earnings of all wage earners. I link these data to individual tax returns, which provides information regarding claimed deductions as well as final taxable earnings. ${ }^{2}$

\footnotetext{
${ }^{1}$ See also Weber (2014), which provides an advancement of the standard IV approach with respect to the choice of the base-year income.

${ }^{2}$ Since most of my analysis focuses on wage earners with zero self-employed income, I use the term taxable earnings instead of taxable income. Note that taxable earnings determine the final tax liability of
} 
Turning toward my results, I first present evidence of diffuse bunching in gross wage earnings (before any deductions) as well as of sharp bunching in taxable earnings after accounting for deductions. Bunching in both earnings measures significantly increased over time since the introduction of the kink. Using only workers at large firms, I find almost identical amounts of bunching, suggesting that the bunching of gross earnings is not driven by wage misreporting but rather represents a (real) earnings supply response. ${ }^{3}$ For the most recent year in my data, I observe $60 \%$ more taxpayers reporting gross wage earnings at the kink than predicted by the counterfactual distribution. I find this excess mass at the kink to become around 1.5 times larger when analyzing taxable earnings (after deductions), providing a first indication that taxpayers partly respond with deduction claiming to the large change in marginal tax rates. The observed excess mass translates into a small but non-negligible earnings elasticity: I estimate a compensated elasticity of 0.1 for taxable earnings, which is in the range of previous studies focusing on wage earners only (e.g., Chetty 2012; Saez et al. 2012; Kleven and Schultz 2014). Corroborating previous research, I also observe the bunching response to be more widespread among female employees (Chetty et al. 2011; Best 2014). In addition, I perform tests suggested by the literature (see, e.g., Tazhitdinova 2015) to uncover aggregate bunching responses driven by firms or unions, but do not find evidence in this direction (see Appendix A.1). ${ }^{4}$

Partitioning the data into groups claiming different levels of deductions, I show further evidence that employees respond strategically to the kink with both their wage earnings and deductions. More precisely, I find individuals with larger deductions to bunch no more at the statutory (=zero deduction) cutoff point with their gross earnings. Instead, I observe those taxpayers to be much more concentrated at the corresponding gross earnings level where, given their level of claimed deductions, their marginal tax rate changes. Similarly, I observe wage earners to have a tendency to report exactly the amount of deductions needed to bunch at the kink. To assess more directly whether taxpayers respond to the kink by claiming higher deductions, I also track the deduction behavior of wage earners over time. I find a significant increase in deductions once taxpayers cross the kink with their (gross) wage earnings, indicating that taxpayers are aware of the kink and adjust their deduction behavior accordingly. Finally, I examine bunching of self-employed taxpayers and find much of the response already before accounting for (personal) deductions, which is in contrast to the behavior of wage earners. While this suggests that access to different adjustment channels affects actual adjustment behavior, I treat this result as informative but not definitive. ${ }^{5}$

\footnotetext{
Footnote 2 continued

wage earners (see Table 1). When analyzing self-employed taxpayers, I use the terms gross and taxable income.

3 It has been frequently shown that underreporting of wages and collusive behavior significantly declines with increasing firm size (Kleven et al. 2011; Kumler et al. 2015).

4 It is important to note that the cutoff point of the kink is not annually adjusted to inflation, making it not a suitable yardstick for unions and employer associations when conducting wage negotiations.

5 Unfortunately, the data on self-employed income do not further distinguish between (reported) business revenue and business expenses, which would be important to further disentangle the different response channels.
} 
My results contribute to existing literature in several ways. First of all, recent studies emphasize the importance of distinguishing reporting responses from changes in earnings supply (e.g., Chetty 2009). The findings indicate that this distinction matters even for lower-income earners with fewer possibilities to shelter taxable income. Furthermore, the study adds to the literature on taxpayers' responsiveness via personal allowances and deductions. ${ }^{6}$ Specifically, I corroborate research showing that deduction behavior does respond to changes in marginal tax rates (Matikka 2016; Doerrenberg et al. 2016), and also relates to recent findings that taxpayers who owe taxes at the end of the year file for deductions to a greater extent (Engström et al. 2015; ReesJones 2018). In addition, my results speak to literature on taxpayer substitution across different tax adjustment channels, showing how access to one channel affects the use of other channels (see, e.g., Klepper and Nagin 1989; Martinez-Vazquez and Rider 2005).

Furthermore, my paper relates to the literature examining bunching responses of taxpayers at kink points (e.g., Saez 2010; Kleven 2016). Studies focusing on selfemployed usually observe large bunching, mainly driven by reporting effects such as retained earnings or income shifting (e.g., Maire and Schjerning 2013; Bastani and Selin 2014). In contrast, studies looking at wage earners mostly found only very limited bunching, pointing at optimization frictions for workers (e.g., Kleven and Waseem 2013). By documenting a slow but gradual rise in bunching after the introduction of the kink, my paper relates to this literature analyzing such frictions (Chetty et al. 2011; Gelber et al. 2016; Kosonen and Matikka 2016; Mortenson and Whitten 2016). Moreover, the findings underpin that also wage earners seek to respond along other margins than labor supply where they are potentially less constrained, for instance via tax deductions.

In addition, my study provides novel elasticity estimates for Austria. There are practically no earlier Austrian studies for taxable earnings elasticities available. The case of Austria is especially interesting due to the very large kink point at the lower middle part of the income distribution. This is in sharp contrast to most other advanced economies which usually set much lower rates at the bottom of the tax schedule to attenuate disincentives to work.

Finally, my study focuses on lower-income wage earners with rather limited possibilities to shelter taxable income but usually more elastic labor supply (such as females or secondary earners). Some studies suggest that sheltering and avoidance/evasion behavior increases with income (e.g., Kreiner et al. 2014; Alstadsaeter et al. 2017). Hence, it would be very interesting to also study deduction and earnings responses of high-income earners. Unfortunately, the two other kinks in the Austrian income tax schedule do not provide enough variation in tax rates to generate visible behavioral responses of taxpayers (see Appendix Fig. 14). Analyzing the relationship between income and deduction behavior in different institutional contexts and settings could present a fruitful avenue for future research.

The paper proceeds as follows. In Sect. 2, I present details on the institutional setting and the Austrian income tax reform of 2005. Section 3 provides information regarding the data I use as well as summary statistics. In Sect. 4, I describe the bunching formula

\footnotetext{
6 The paper is also related to literature showing that charitable donations are responsive to tax incentives (see, e.g., Fack and Landais 2010; Scharf and Smith 2015; Duquette 2016 for recent contributions).
} 
Table 1 Calculation of tax liability (2011)

Sum of annual gross earnings

- Deductions for income-related expenses

= Adjusted gross earnings

- Deductions for personal expenses

$=$ Taxable earnings

$\Rightarrow$ Applying kinked tax schedule to taxable earnings

$=$ Tax liability

- Tax credits

Tax due

and estimation framework. Section 5 presents the empirical analysis using bunching estimations. Section 6 concludes.

\section{Institutional background and the income tax reform of 2005}

\subsection{The personal income tax in Austria}

The individual is the taxing unit in the Austrian personal income tax code. Hence, there is no taxation of married couples or households. Table 1 depicts the basic steps for the calculation of the personal income tax for wage earners as defined by the Austrian tax law.

In a first step, earnings from all employment relationships during a fiscal year are added up to determine an individual's sum of annual gross earnings. ${ }^{7}$ Note that annual gross earnings are already adjusted by mandatory social security contributions such as pension, health and unemployment insurance, which are not subject to income taxation. The gross earnings can then be reduced by claiming (itemized) deductions when filing a tax return at the end of the year. Austria makes extensive use of monthly income tax withholding via the employer and thus does not require wage earners to file a tax return. However, a majority (ca. 75\%) of all wage earners file a tax return since the Austrian tax code allows for a set of deduction possibilities. ${ }^{8}$. When a taxpayer decides to file taxes at the end of the year, the tax return will come pre-filled with the gross earnings reported by the employer. Furthermore, employers are required to issue a monthly payslip to their workers stating their monthly gross earnings as well as any taxes withheld, which gives wage earners a good sense of how much tax they already paid and whether claiming deductions at the end of the year might result in a

\footnotetext{
7 Please note that welfare transfers such as unemployment benefits are tax exempt and hence not part of calculating the personal tax liability. Further, capital income in Austria is taxed at the source at a favorable rate of $25 \%$ and thus usually absent when filing personal income taxes.

8 For wage earners with income below the first bracket cutoff, a small negative income tax credit is applicable. Since this tax credit requires filing a tax return, even taxpayers not liable for income taxation have an incentive to hand in a tax return.
} 
tax refund. It is important to note that for wage earners who do not file a tax return, the gross earnings become taxable earnings which will then be used as the tax base to calculate the tax liability.

As illustrated by Table 1, deduction possibilities fall broadly into two categories. The first one is income-related deductions. Examples for such deductions are costs for professional training and education, expenses for work equipment (e.g., technical literature or work clothes), work-related travel or commuting costs and any fees for mandatory membership in certain organizations such as the Austrian Chamber of Labor. Non-itemizing taxpayers receive a small general allowance of EUR 132. The second category is deductions for personal expenses. Those include voluntary premiums for personal insurance (health, accident, life insurance), charitable giving, child care costs, expenses on constructing or maintaining the living accommodation, tax consultant fees and mortgage interest payments for private housing. The standard allowance for personal expenses when a taxpayer does not itemize is EUR 60. Note that some of the deductions are capped per item or by group of items.

\subsection{The Austrian income tax reform of $\mathbf{2 0 0 5}$}

In 2005, a comprehensive tax reform came into force in Austria. The reform was aimed to make the tax schedule more transparent and easier to understand. Before 2005, the Austrian tax schedule consisted of five statutory brackets (see Table 2) combined with a large general tax credit for low-income earners, which was phased out with increasing income and depending on the taxpayer's status (single-earner, single-parent, retiree, individuals with self-employed income, etc.). This resulted in a rather complex tax schedule, with exemption rules and effective marginal tax rates difficult to understand, especially for low-income taxpayers. With the tax reform of 2005, the general tax credit as well as the bottom bracket got removed, which raised the tax-free amount to 10,000 EUR of taxable earnings. ${ }^{9}$ This created a large and simple first kink point for all individuals, especially salient for low-income earners and part-time workers. After the reform, marginal tax rates increase by as much as 38.33 percentage points at this new cutoff point (implying a change of $0.483 \log$ points in the net-of-tax rate). Since 2005 , the structure of the tax schedule as depicted in Table 2 remained unchanged, except for some small adjustments in 2009 when cutoffs for the first and the top bracket were slightly raised to 11,000 EUR and 60,000 EUR, respectively (with new marginal tax rates of 36.5, 43.2 and 50\%, respectively). Furthermore, it is important to note that there are no other changes at the cutoffs besides the income tax schedule. For instance, employers have to start withholding (and reporting) social security contributions via an employees' payslip when wage earnings are as low as 375 EUR per month (2011). Figure 1 graphically illustrates the three income tax brackets of the new tax schedule after the reform of 2005 and shows the previous schedule as a comparison. Finally, I want to emphasize that my identification strategy does not exploit the tax reform of

\footnotetext{
9 Please note that all wage earners are still granted two minor general tax credits of 54 and 291 EUR, respectively. Thus, the actual threshold where marginal tax rates change is at around 10,900 EUR (345 EUR divided by the marginal tax rate of $38.33 \%$ ). In all bunching analyses, I use this actual threshold, and not the statutory one.
} 
Table 2 Marginal tax rates and bracket cutoffs before and after 2005 (in EUR)

\begin{tabular}{lcll}
\hline Pre-reform schedule & MTR $(\%)$ & Post-reform schedule & MTR $(\%)$ \\
\hline $0-3640$ & 0 & - & - \\
$3640-7270$ & 21 & $0-10,000$ & 0 \\
$7270-21,800$ & 31 & $10,000-25,000$ & 38.33 \\
$21,800-50,870$ & 41 & $25,000-51,000$ & 43.6 \\
$>50,870$ & 50 & $>51,000$ & 50 \\
\hline
\end{tabular}

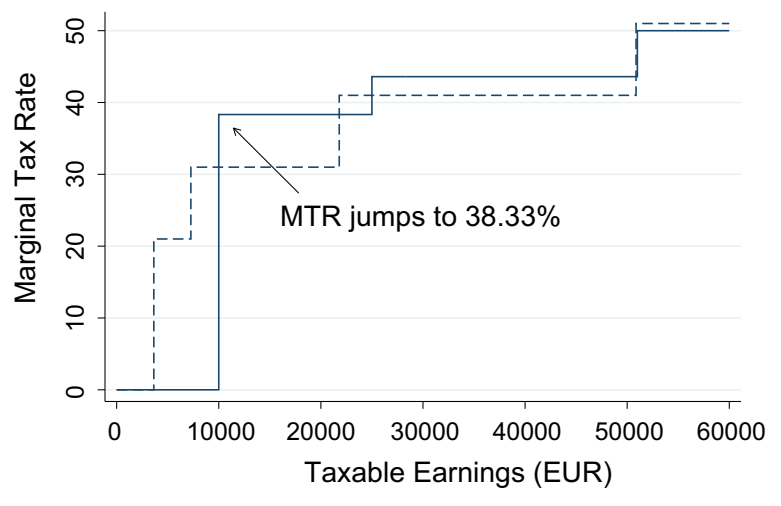

----- Pre-reform schedule — Post-reform schedule

Fig. 1 The Austrian income tax schedule before and after 2005

2005 to construct instruments, but uses bunching estimators and tax return data after 2005 to study behavioral responses (tax return data before 2005 is not available).

\section{Data and summary statistics}

\subsection{Data}

This project builds on sets of high-quality administrative data covering all Austrian wage earners to study behavioral responses to taxation. The data stem from three different sources which can be linked: First, I have access to the whole population of Austrian payslips (comparable to W-2 forms in the USA) covering all employees and their gross earnings before deductions. This third-party reported earnings data also include information regarding social security contributions and taxes withheld by the employer. Since I aim to separate between earnings supply and deduction responses as cleanly as possible, I use taxpayers with only payslip-recorded earnings and exclude all individuals with self-employed income. ${ }^{10}$ Second, I link these payslip data to the universe of tax returns filed by Austrian wage earners. This tax return data

$\overline{10}$ In Sect. 5.2, I contrast my results with data on self-employed taxpayers. 
contains information regarding claimed deductions as well as the final taxable earnings. I observe the total amount taxpayers deduct in each of the deduction categories as displayed in Table 1, but not the single line items. Since most items within the two deduction categories represent individual choices of the taxpayer, I usually report the total amount of claimed deductions (i.e., the sum of income-related deductions and personal expenses). ${ }^{11}$ Focusing on the total amount of claimed deductions is also useful since it is this sum of deductions which determines a taxpayer's final taxable earnings, the key figure to which the kinked tax schedule is then applied. Overall, the time period covered by the data is 2005-2011.

Finally, I augment my analysis with tax return data of self-employed taxpayers. Unfortunately, these data contain much less information about the individual taxpayer. For instance, the data on the self-employed only provide two income measures, namely gross income (= business revenue minus business expenses) and taxable income (gross income minus all other deductions such as personal expenses). Importantly, these other deductions comprise the same deduction items as for wage earners, e.g., premiums for personal insurance (health, life insurance), charitable giving, child care costs, tax consultant fees or mortgage interest payments for private housing.

\subsection{Summary statistics}

Following standard practice in the literature (e.g., Saez et al. 2012), I apply some restrictions to my analysis sample. First, I remove retirees and individuals currently doing an apprenticeship from the sample. Further, I exclude taxpayers working in 'Mini-Jobs' which are subject to a different social security regime, not eligible for any deductions and restricted to gross wage earnings of less than 375 EUR a month (2011). I am finally left with a sample of approximately 21 million observations stemming from around 4 million wage earners.

Table 3 provides descriptive statistics for all wage earners and for wage earners located close to the kink (defined as having taxable earnings within 4 bins on each side of the kink), separately. In the whole sample, wage earners are on average 39 years old, $44 \%$ are female, and $19 \%$ work part-time. Seventy-three percent of all wage earners file a tax return at the end of the year. The mean taxable earnings are 22,277 EUR and, on average, wage earners claim around 1000 EUR in total deductions. Looking only at wage earners close to the kink, I find a mean age of 37 years, $65 \%$ women, and the share working part-time being around one-third. The mean taxable earnings are 11,546 EUR, with average deductions equal to 750 EUR. I observe some degree of variance in the amount of deductions claimed, indicated by a fairly high standard deviation. ${ }^{12}$ There are also some differences regarding job tenure or the

\footnotetext{
11 Please note that in Austria, all mandatory social security contributions are fully tax exempt and hence, not part of the income-related or special deductions. This is a qualitatively different institutional setting than, e.g., in Germany, where income-related deductions also include social security contributions, which are third-party reported and not subject to a choice of whether to claim them or not on the tax return (see Doerrenberg et al. 2016).

12 Again, I want to emphasize that in contrast to other countries such as Germany, all mandatory contributions to public pension, health and unemployment insurance are automatically subtracted from gross
} 
Table 3 Summary statistics of wage earners, 2005-2011

\begin{tabular}{|c|c|c|c|c|}
\hline & \multicolumn{2}{|c|}{ All wage earners } & \multicolumn{2}{|c|}{ Inside bunching window } \\
\hline & Mean & $\mathrm{SD}$ & Mean & $\mathrm{SD}$ \\
\hline Age & 39.5 & 10.7 & 37.2 & 11.1 \\
\hline Female & 0.439 & 0.496 & 0.653 & 0.476 \\
\hline White-collar worker & 0.462 & 0.499 & 0.411 & 0.492 \\
\hline Blue-collar worker & 0.368 & 0.482 & 0.489 & 0.498 \\
\hline Non-native & 0.194 & 0.398 & 0.268 & 0.443 \\
\hline Working part-time & 0.196 & 0.397 & 0.367 & 0.482 \\
\hline Job tenure & 11.3 & 4.3 & 9.9 & 4.9 \\
\hline Gross earnings & 23,084 & 23,072 & 12,135 & 2377 \\
\hline Taxable earnings & 22,277 & 22,907 & 11,546 & 1404 \\
\hline Total deductions & 1009 & 1683 & 748.147 & 1183 \\
\hline Fraction filing tax return & 0.731 & 0.444 & 0.785 & 0.411 \\
\hline Fraction receiving commuter tax break & 0.325 & 0.468 & 0.297 & 0.457 \\
\hline Observations & \multicolumn{2}{|c|}{$21,196,743$} & \multicolumn{2}{|c|}{$3,776,292$} \\
\hline Unique individuals & \multicolumn{2}{|c|}{$4,105,634$} & \multicolumn{2}{|c|}{$1,588,967$} \\
\hline
\end{tabular}

composition of the work force. In sum, it is important to keep in mind that the analysis focuses on bunching of lower-income wage earners, which may differ from the overall population in certain aspects (e.g., with respect to the extensive vs. intensive margin responses).

\section{Estimation procedure using the bunching formula}

Bunching estimations received increasing attention in recent years to study behavioral responses to taxation. Specifically, it has been argued that kink points can provide a viable source of identification to recover credible estimates of behavioral parameters (Kleven 2016). In addition to methodological considerations, I decided to use bunching estimations for the following reasons: The first one has to do with data availability. While there do exist Austrian payslips as well as social security data for the years before 2005, I do not have access to tax return and deduction information prior to 2005 . Hence, I am not in the position to study deduction or taxable earnings responses to the large tax reform of 2005 using other methods such as tax instruments. Second, the tax reform of 2005 created a simple tax schedule with an easy-to-understand tax-free zone not blurred with large phase-in tax credits, making it rather straightforward for taxpayers to understand at which income level marginal tax rates change substantially. Hence, focusing on behavioral responses to the first

earnings and not part of any deductions. Hence, total deductions cover items which to a large extent represent choices of the individual and might at least partly be motivated by sheltering/deduction behavior serving the purpose of reducing tax liability. 
kink point follows the idea to exploit large and salient features of the tax code to receive the most credible estimates of behavioral responses to taxation (Chetty 2012). Third, mechanical effects induced by simultaneous tax rate and tax base reforms can make identification of a deduction response sometimes difficult (see Saez et al. 2012). Since I do not rely on tax reforms to construct instruments but focus on a period without major tax base changes, my results should be more robust to this challenge.

The estimation procedure used in this study will draw on Chetty et al. (2011), which modify Saez's original formula in two ways: First, their bunching estimation uses the observed densities around the kink to inform one counterfactual density, whereas Saez (2010) constructs two counterfactual densities for both sides of the kink separately. Second, Saez's procedure assumes that the underlying distribution has a trapezoid shape and uses a parametrized model. In contrast, Chetty et al. (2011) apply a more flexible specification to estimate the counterfactual distribution nonparametrically. More precisely, they fit a polynomial to the income distribution while omitting an income window surrounding the kink and then adjust the mass of the counterfactual distribution so that it integrates to one. Those alterations aim to account better for the curvature of the underlying density function than the original Saez formula. ${ }^{13}$

In what follows I aim to describe the bunching estimation technique used here in the simplest possible way. ${ }^{14}$ First, I collapse data into 500 EUR wide bins, where each bin $j$ stands for an earnings level $Z_{j}$. The earnings level $Z_{j}$ represents the mean absolute earnings distance between the observations falling within earnings bin $j$ and the kink point. Hence, $Z_{j}$ measures the distance between bin $j$ and the kink point. In line with previous studies using bunching techniques, I then define a bunching window of $[-R, R]$ by visual inspection of the raw data. I use 4 bins on each side of the kink as the baseline for the bunching window. ${ }^{15}$ The number of individuals in earnings bin $j$ is given by the nonparametric regression:

$$
C_{j}=\zeta\left(Z_{j}, R\right)+\eta_{j}
$$

where $\zeta$ is a 7 th degree polynomial in $Z_{j}$ including dummy variables for observations in the bunching window $R$. The term $\eta_{j}$ accounts for errors in the polynomial fit. Bunching is then estimated by relating the (actual) number of taxpayers $\hat{B}$ to the average density of the counterfactual distribution in the bunching window $[-R, R]$. More specifically, bunching responses are paralleled by an excess mass of taxpayers $\hat{b}$ at the kink, which can be calculated as

\footnotetext{
13 My results remain qualitatively unaffected when I estimate bunching using simpler approximations, for instance in the spirit of Saez (2010).

14 I thank Chetty et al. (2011) for making their code publicly available. For a more detailed description of their estimation procedure, I want to refer the interested reader to this paper.

15 My main results stay qualitatively the same when applying adjustments of the bin width or bunching window. See Appendix A.3.
} 


$$
\hat{b}=\frac{\hat{B}}{\sum_{j=-R}^{R}\left(\frac{\hat{C}_{j}}{2 R+1}\right)}
$$

Note that $\hat{C}_{j}$ denotes the predicted values from regression (1). I use a bootstrap procedure to obtain standard errors for the excess mass $\hat{b}$ by drawing from the estimated errors with replacement and compute $\hat{b}$ repeatedly.

To calculate the implied elasticities, I then relate the excess mass to the change in the net-of-tax rate:

$$
\epsilon=\frac{\hat{b}}{k * \log \left(\frac{1-t_{1}}{1-t_{2}}\right)}
$$

with $k$ being the earnings level where the tax rate increases from $t_{1}$ to $t_{2}$ (i.e., the kink point). Note that this measure is not unit-free and depends on the choice of bin width $d$. The elasticities reported in the paper are expressed in units of $d$ and hence, invariant to the unit of measurement (see also Bastani and Selin 2014).

An important identification assumption underlying causal inference using bunching estimation is that the earnings distribution would be smooth in absence of the kink point. I can relax this assumption by studying changes of the earnings distribution since the tax reform of 2005. Given the optimization frictions (such as lack of information or adjustment costs) wage earners are facing when confronted with changing tax incentives, I expect bunching to build up over time (see, e.g., Kleven and Waseem 2013; Chetty et al. 2013). Studying the evolution of the bunching response on a yearby-year basis since the introduction of the kink, I am able to document how the earnings distribution is increasingly deformed since $2005 .^{16}$

\section{Empirical analysis}

\subsection{Wage earners}

I begin with examining the pattern of bunching in gross earnings (before any deductions) and taxable earnings (after deductions) separately. I calculate the distance between the respective earnings measure and the first kink point for each observation. Thus, the computed earnings distance has a value of zero for those exactly at the bracket cutoff. I then put taxpayers into 500 EUR wide bins of earnings distance to the kink ( -250 to 250,250 to 750 , etc.) and pool data over all years. I plot histograms

\footnotetext{
16 Few papers using bunching estimators have accounted for optimization frictions when estimating earnings elasticities (Gelber et al. 2016; Kosonen and Matikka 2016). To successfully account for frictions requires either a notch, differently sized kinks located at different earnings thresholds, or changes in the size of a certain kink over time (Kleven 2016). Since I lack a useful source of variation during the time of my study, I desist from quantifying such optimization frictions but document them qualitatively. Hence, I interpret the taxable earnings elasticity as a lower bound of the underlying structural elasticity. However, frictions are typically less relevant when changes in the tax rate schedule are large, since they induce much bigger utility benefits from changing behavior (Chetty 2012).
} 
of bin counts around the kink point, demarcated by the vertical line at zero which represents the kink where marginal tax rates change. Further, I fit the polynomial to the bin counts, excluding the bunching window of [ -4 Bins, +4 Bins] (as described in Sect. 4). The solid red curve in the histogram displays this counterfactual distribution, and I report the estimate of the excess mass $\hat{b}$ in each figure.

Panel A of Fig. 2 plots gross earnings of all Austrian wage earners from 2005 to 2011. There is a clearly visible hump around the first kink point in an otherwise smooth and normally shaped earnings distribution. The calculated excess mass of taxpayers at the kink is 0.40 and highly statistically significant. This translates into an additional mass of wage earners of $40 \%$ compared to the (predicted) average mass of the counterfactual gross earnings distribution. One might wonder why the bunching response of gross earnings is not sharp but somewhat diffuse. This can potentially be attributed to various factors. First, it might prove difficult for wage earners to control their wage earnings perfectly. This seems especially important in the Austrian context where kinks are not regularly adjusted for inflation while unions negotiate annually for higher wages on behalf of the majority of wage earners. Second, much of the sharp bunching responses of the self-employed documented in the literature has been associated with reporting effects such as income shifting rather than a real earnings response (e.g., Maire and Schjerning 2013; Bastani and Selin 2014). In contrast, the third-party reported gross earnings (before any deductions) I report here should come very close to an actual earnings response. ${ }^{17}$ Finally, it could be the case that some wage earners may locate well to the right of the kink with their gross earnings but target the kink with their taxable earnings through deductions. Panel B of Fig. 2 gives a first indication that this is indeed the case. This time, I display the taxable earnings distribution of all wage earners. Note that I again plot the entire population of wage earners, i.e., for those who do not file a tax return I use their gross earnings as taxable earnings (because for non-filers, gross earnings form the tax base to calculate tax liability). Hence, I do not select on filing a tax return, which might be endogenous. The taxable earnings distribution plotted in Panel B shows a more concentrated spike around the first kink, with a calculated excess mass of 0.61 . This means that after accounting for claimed deductions, the excess mass becomes ca. 50\% larger than for gross earnings. Relating the excess mass of the taxable earnings distribution to the excess mass of the gross earnings distribution, I receive a ratio of 1.5. The emergence of a spike in the taxable earnings distribution provides first evidence that taxpayers (partly) respond with deduction claiming to the change in marginal tax rates at the kink.

The behavior that wage earners target the kink with their deductions is further documented in Fig. 3, which displays gross earnings distributions of wage earners with different amounts of claimed deductions. To construct the figure, I partition the sample of wage earners into groups claiming deductions worth 250-750, 750-1250, 1250-1750, etc. Panel A of Fig. 3 depicts the gross earnings distribution (before

\footnotetext{
17 It has been frequently shown that underreporting of wages and collusive behavior declines with increasing firm size (Kleven et al. 2011, Kumler et al. 2015). Appendix Fig. 10 replicates Panel A of Fig. 2 for wage earners working at firms with more than 250 employees. I find very similar bunching of gross earnings for this sample, suggesting that the bunching response is unlikely to be driven by wage misreporting.
} 


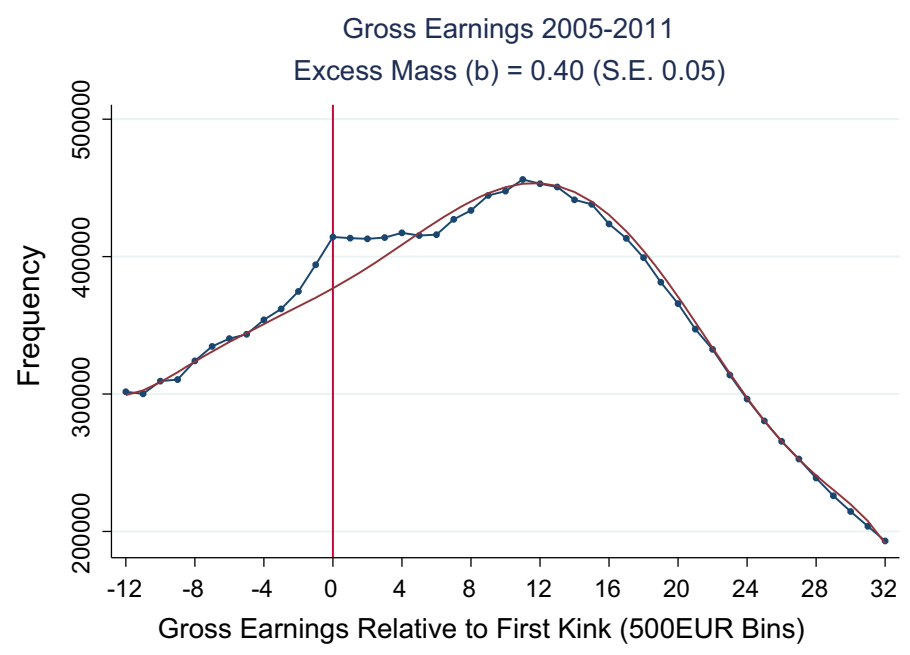

Panel A

Taxable Earnings 2005-2011

Excess Mass $(b)=0.61$ (S.E. 0.05)

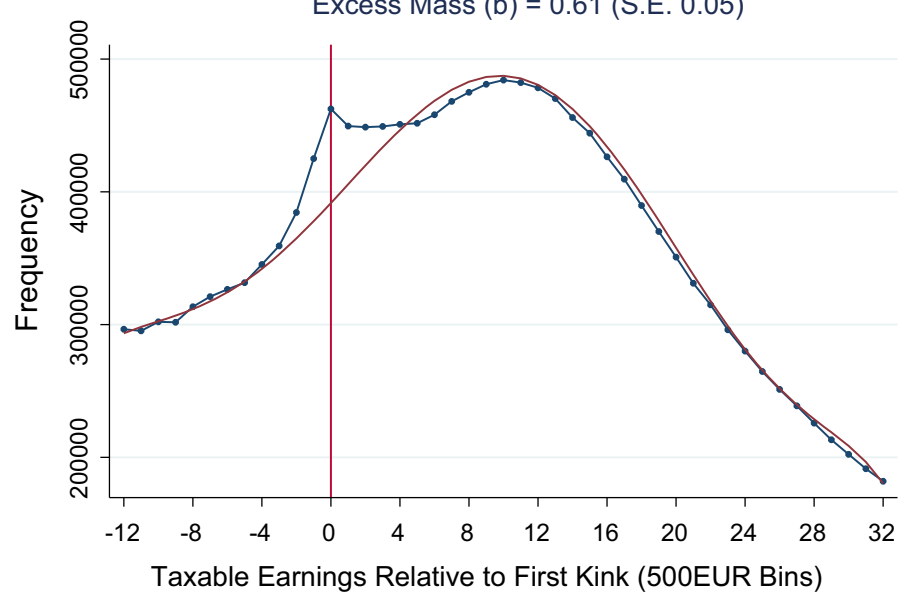

Panel B

Fig. 2 Gross earnings versus taxable earnings distribution of wage earners (2005-2011). Notes: Panel A Gross earnings (before any deductions) of all Austrian wage earners from 2005 to 2011. Panel B Taxable earnings (after deductions) of all Austrian wage earners from 2005 to 2011. The series shown in dots is a histogram of gross earnings (or taxable earnings, respectively) relative to the first tax bracket. Each point shows the number of observations in a 500 EUR wide bin. The solid line beneath the empirical distribution is a seventh-degree polynomial fitted to the empirical distribution excluding a bunching window of 4 bins on each side of the kink, as described in Sect. 4. The area between the empirical distribution and the polynomial fit represents the estimated excess mass at the kink

deductions) of taxpayers claiming between 250 and 750 EUR of deductions on their tax return at the end of the year. These individuals do not start paying taxes at the solid line at zero but at the dashed line at bin one. It is evident from the graph that 


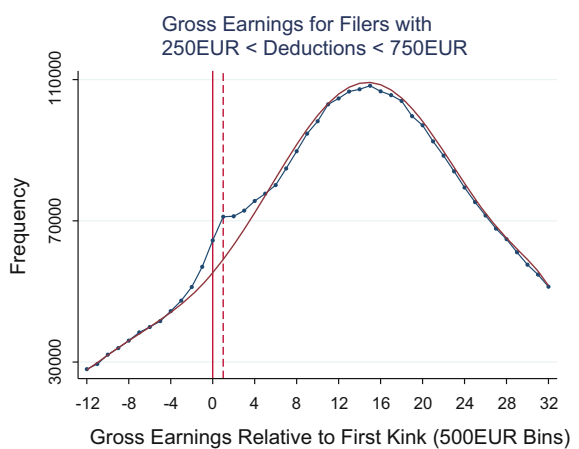

Panel A

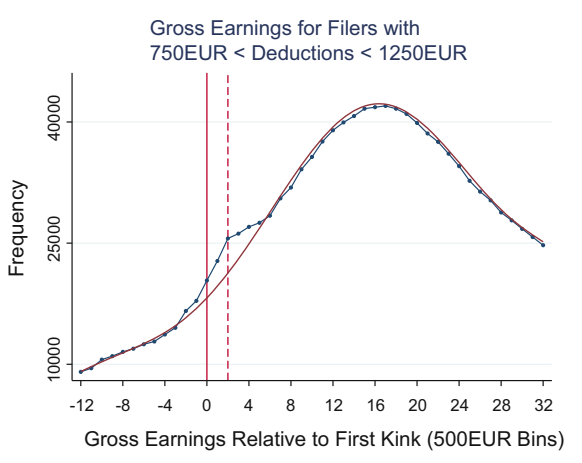

Panel B

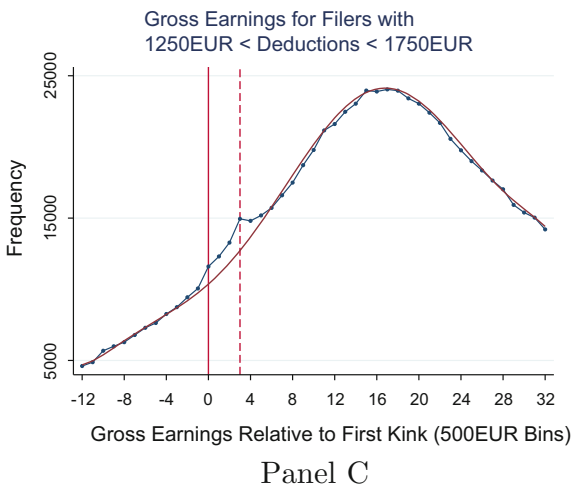

Fig. 3 Gross earnings distributions of taxpayers with different levels of deductions (2005-2011). Notes: These figures plot the empirical distribution of gross earnings (before deductions) for taxpayers with different levels of claimed deductions. Panel A Gross earnings of wage earners claiming between 250 EUR and 750 EUR, Panel B claiming between 750 EUR and 1250 EUR and Panel C claiming between 1250 EUR and 1750 EUR. The solid vertical lines show the statutory cutoff point for individuals with zero deductions. The dashed vertical lines show the corresponding cutoff point where these taxpayers, given their level of claimed deductions, actually start paying the higher tax rate

the highest point of the excess mass shifts exactly one 500 EUR wide bin to the right. Panel B plots the gross earnings distribution of taxpayers claiming 750-1250 EUR, and I observe a further shift to the right by another gross earnings bin. This pattern continues when displaying taxpayers claiming 1250-1750 EUR of deductions, where now the bunching is concentrated around three bins away from the statutory (zero deduction) cutoff point. In sum, Fig. 3 provides evidence about the responsiveness of wage earners to the tax rate change. It suggests that wage earners are aware of the kink and adjust their behavior in order to bunch with their taxable earnings. ${ }^{18}$

To assess more directly the responsiveness of deduction behavior due to the kink, Fig. 4 shows mean deduction growth compared to current taxable earnings. The idea is to explore whether individuals in the vicinity of the kink have a stronger increase in

\footnotetext{
18 I also illustrate the targeting behavior of wage earners by calculating normalized deductions. Please see Appendix A. 2 for details.
} 
their claimed deductions than individuals in other parts of the earnings distribution. For both panels, I put taxpayers into 1000 EUR wide bins of taxable earnings at time $t$ and plot it against the percentage change of claimed deductions within each bin from $t$ to $t+1 .{ }^{19}$ Furthermore, I add a quadratic fit of the bin averages (excluding the bin at the cutoff) to approximate the counterfactual mean deduction growth at a certain earnings level. Panel A focuses on taxpayers who experience an increase in annual gross earnings from $t$ to $t+1$. Thus, taxpayers in Panel A who are close to the kink at time $t$ will be pushed beyond the nominally rigid cutoff point by their gross earnings growth. In order to avoid crossing the kink and being taxed, individuals may offset their gross earnings growth by claiming higher deductions. ${ }^{20}$ I observe a sharp increase in claimed deductions for wage earners located close to the kink point at time $t$, with a much higher average growth rate in the deduction amount than people to the left- or right-hand side of the kink. Panel B of Fig. 4 depicts taxpayers who experience a decrease in annual gross earnings from $t$ to $t+1$. In contrast to Panel $\mathrm{A}$, I do not find a deviation in deduction growth at the cutoff point for those wage earners. ${ }^{21}$ In sum, the presence of a spike in deduction growth exactly at the cutoff point for taxpayers with a positive change in gross earnings suggests that wage earners are aware of the kink and increase their claimed deductions once they cross it.

The identifying assumption underlying causal inference using bunching techniques is that the earnings distribution would be smooth in the absence of the kink. I can relax this identifying assumption by exploiting the tax reform of 2005 as a natural experiment. Hence, I can study changes in the earnings distribution after the introduction of this large and salient first kink. First, I start with the gross and taxable earnings distribution of 2005, the year of the reform. Panels A of Fig. 5 displays the gross earnings distribution of 2005, and Panel B depicts the taxable earnings distribution of the same year. There is only a tiny distortion visible in either distribution, with an insignificant excess mass for both earnings measures. In the following years, the bunching response is steadily growing, with significant excess masses for every year from 2007 onwards. The two lower panels of Fig. 5 display the distributions for $2011 .^{22}$ The panels show an excess mass of 0.60 for gross earnings and 1.01 for taxable earnings in 2011, both highly statistically significant. Again, the excess mass is found to be ca. 50\% larger for taxable than for gross earnings and much more concentrated, suggesting that taxpayers in part do respond with deduction claiming to target the kink point. Furthermore, it should be noted that the excess masses observed for 2011 translate into small but non-

\footnotetext{
19 Using 500 EUR wide bins instead of 1000 EUR bins or using gross earnings instead of taxable earnings as the assignment variable do not change the overall pattern of Fig. 4. By choosing larger bins I aim to capture taxpayers intertemporally affected by the kink in one bin, as put forward by the literature on dynamic bunching (e.g., Almunia and Lopez-Rodriguez 2015; Marx 2015)

20 Please note that I again do not select on filing a tax return but use the entire population in my sample. This means that for those who do not file a tax return I use the standard deduction for income-related deductions and personal expenses, respectively. My results stay qualitatively the same when using only wage earners who file a tax return.

21 This missing drop in deductions at the cutoff can be reconciled by models of reference-dependent preferences, where taxpayers perceive increases in their tax liability differently than decreases (see, e.g., Engström et al. 2015; Rees-Jones 2018).

22 Appendix Fig. 11 shows also distributions for every other year in the data.
} 


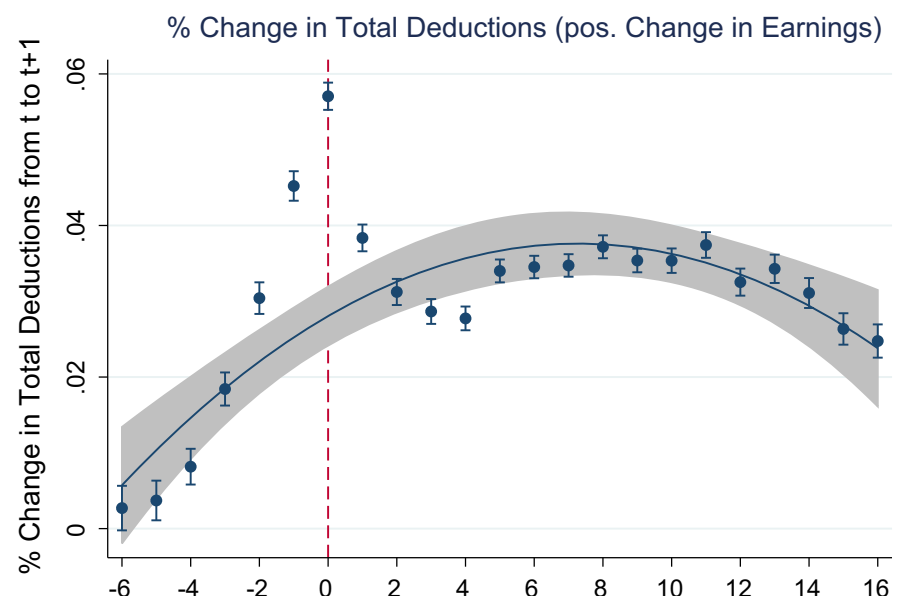

Taxable Earnings Relative to First Kink at Time t (1000EUR Bins)

Panel A

$\%$ Change in Total Deductions (neg. Change in Earnings)

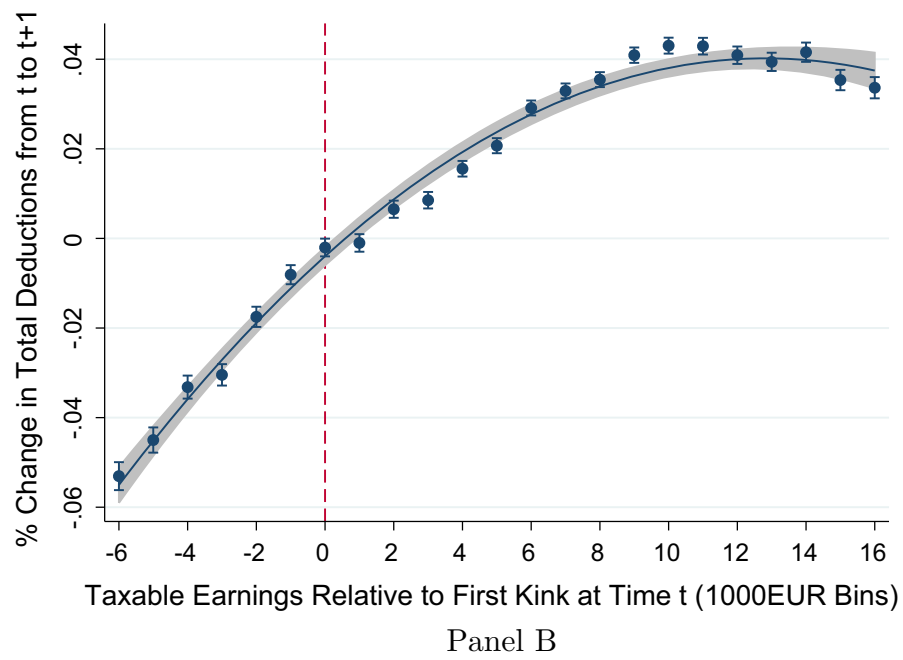

Fig. 4 Patterns of deduction growth around kink point. Notes: This figure shows mean deduction growth compared to current taxable earnings. Both diagrams display the mean growth in claimed deductions, defined as the mean of $\left[\ln \left(\right.\right.$ total deduction $\left._{t+1}\right)-\ln \left(\right.$ total deductions $\left.\left._{t}\right)\right]$. The horizontal axis shows taxable earnings for year $t$ in both panels. Panel A (B) focuses on taxpayers with an increase (decrease) of gross earnings from $t$ to $t+1$ only. The solid blue curve is a quadratic fit of the bin averages. The whisker of each dot marks the $95 \%$ confidence interval of the bin averages. The solid vertical line displays the cutoff point of the first kink 


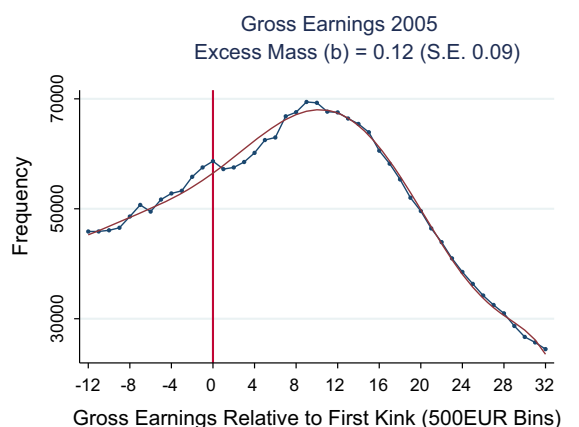

Panel A

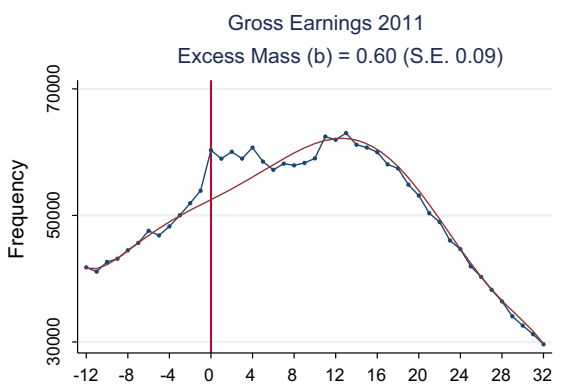

Gross Earnings Relative to First Kink (500EUR Bins)

Panel C
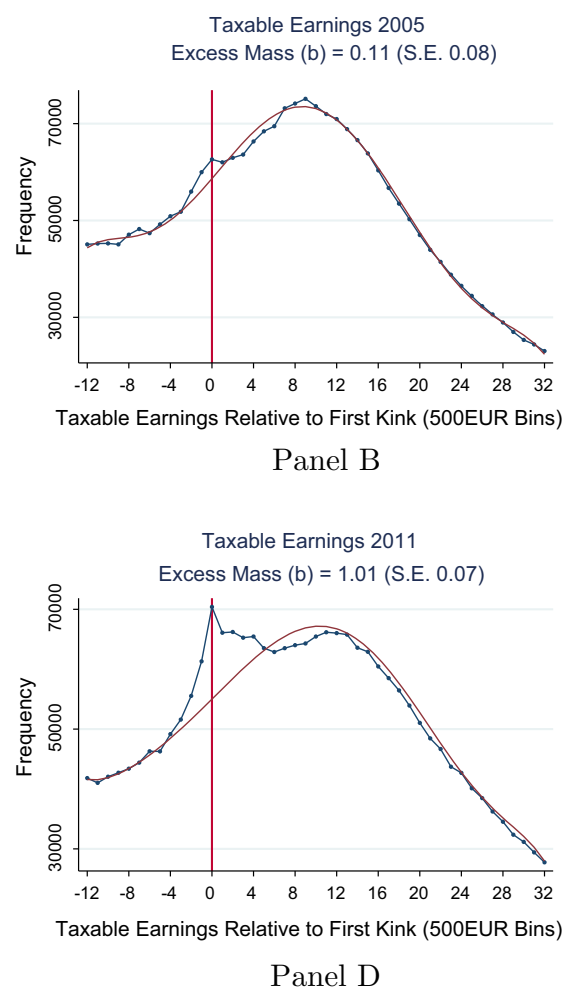

Fig. 5 Increase in bunching over time. Notes: These figures plot the empirical distribution of gross earnings and taxable earnings of all wage earners in 2005 and 2011, respectively. The solid vertical lines mark the first kink point in the respective year. When estimating the counterfactual, a bunching window of 4 bins is excluded on each side of the kink. Each panel also displays the counterfactual distribution and excess mass, computed as described in Sect. 4. Relating the excess mass for taxable earnings to the change in the net-of-tax rate implies an elasticity of $\epsilon=0.0$ for 2005, and of $\epsilon=0.1$ for 2011, respectively

negligible earnings elasticities: Relating the observed excess mass for taxable earnings to the change in the net-of-tax rate at the kink, I receive a compensated elasticity of $\epsilon=0.1\left(\epsilon=0.06\right.$ for gross earnings). ${ }^{23}$ They are also well in the range of previous studies focusing on wage earners only (see Chetty 2012; Saez et al. 2012; Kleven and Schultz 2014).

In line with previous literature (Chetty et al. 2011; Best 2014) I also observe larger responses of women to the tax rate change. The upper panels of Fig. 6 plot gross earnings distributions for women and men separately (2005-2011). For women, I observe a clear spike in the distribution exactly around the cutoff, which is statistically significant (Panel A). Panel B for men displays only diffuse bunching, with a slight

\footnotetext{
23 Since I am not in a position to quantify optimization frictions (see Footnote 18), I treat my elasticity estimates as lower bounds of the underlying structural elasticity. However, it is important to note that frictions are typically less relevant when changes in the tax rate schedule are large, since they induce much bigger utility benefits from changing behavior (Chetty 2012).
} 

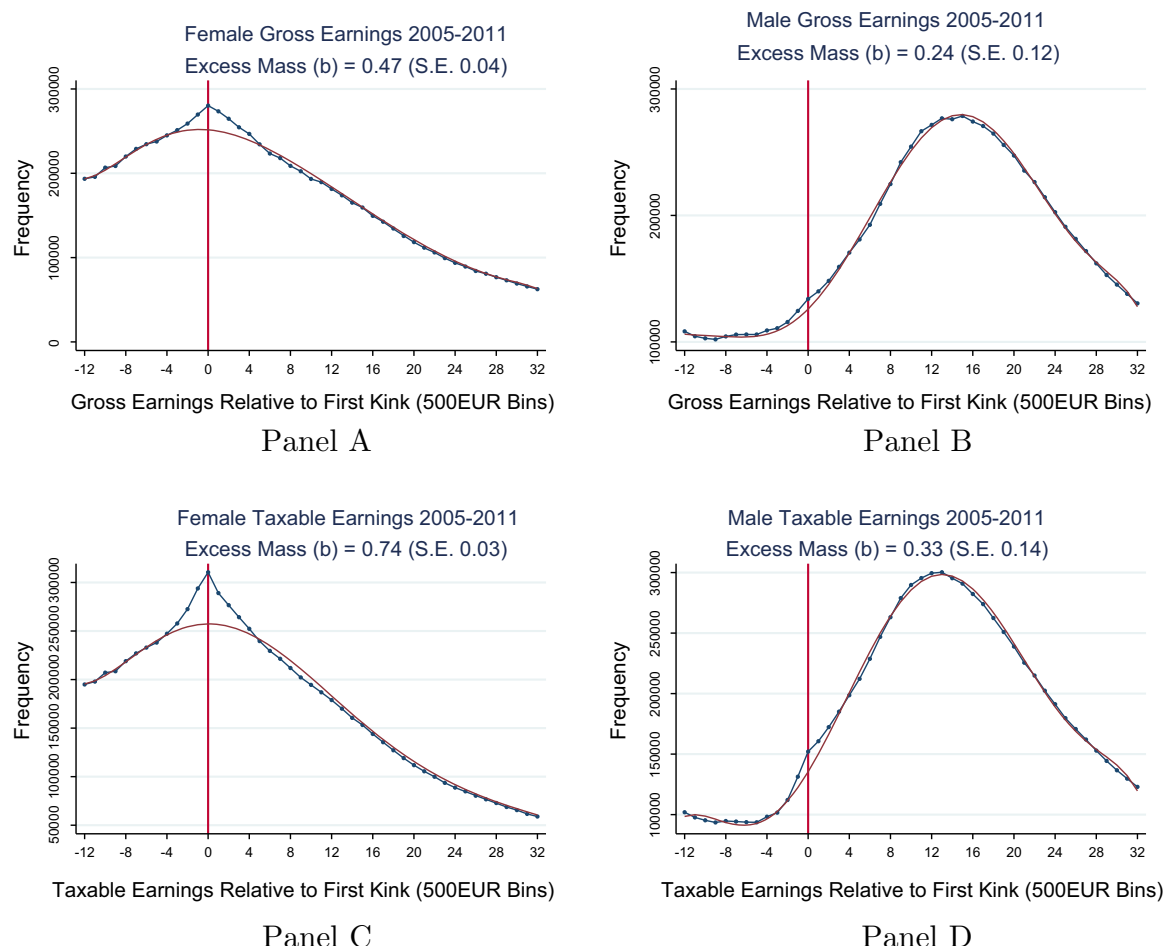

Fig. 6 Gross and taxable earnings of male versus female wage earners (2005-2011). Notes: These figures plot the empirical distribution of gross and taxable earnings of male and female wage earners separately (2005-2011). Panel A shows gross earnings of all female wage earners, while Panel B displays their taxable earnings. Panel C, D Plot male gross and taxable earnings, respectively. Each Panel also displays the counterfactual distribution and excess mass, using a bunching window of 4 bins to each side of the kink

hump around the kink point and a borderline significant excess mass. Importantly, I find the bunching response to be much larger for both groups when looking at taxable earnings instead of gross earnings (Panel C and D). In this case, the excess mass at the kink for both men and women increases by ca. 50\%, suggesting that both groups of taxpayers target the kink with their deductions. ${ }^{24}$

To shed additional light on the differing gross earnings responses of men and women, I build on Chetty et al. (2011) and explore the role of differences across occupations and industries in the heterogeneity of the bunching. To do so, I reweight the sample of male wage earners to match the observed distribution of occupations across industries for women. Specifically, I reweight an observation in the occupation $i$ and industry $j$ by $\frac{p_{i j}}{1-p_{i j}}$, where $p_{i j}$ is the probability that a wage earner working

\footnotetext{
24 One may be concerned that the specific shape of the female earnings distribution with its mode being close to the kink exaggerates the bunching estimate. However, running the analysis for 2005 only shows no significant excess mass for females, though the earnings distribution has its mode already close to the kink in that year (results available upon request). This goes against the notion that it is the specific shape of the female earnings distribution which creates the excess mass picked up by the bunching estimator.
} 


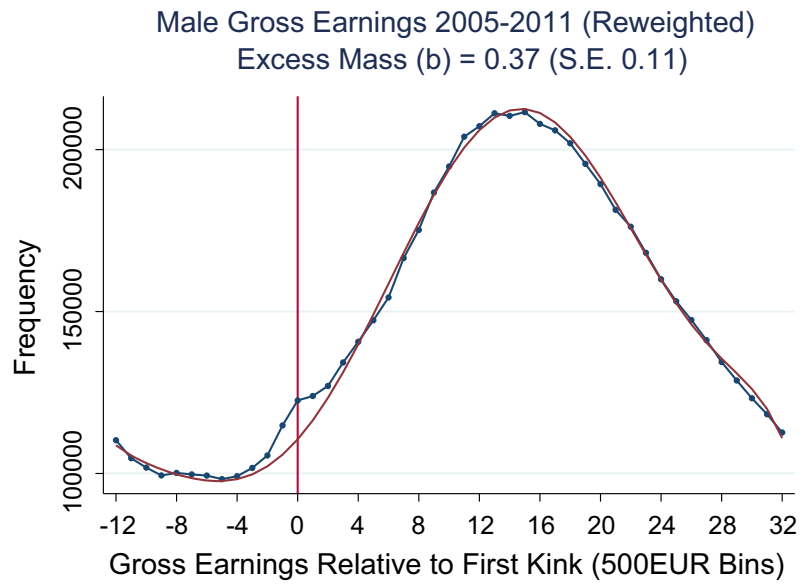

Fig. 7 Occupational and Industry Heterogeneity: Reweighted distribution of male wage earners. Notes: The series shows reweights of the observations for men to match the occupational and industry distribution of women. Building on Chetty et al. (2011), an observation in the occupation $i$ and industry $j$ is reweighted by $\frac{p_{i j}}{1-p_{i j}}$, where $p_{i j}$ is the probability that a wage earner working in occupation $i$ and industry $j$ is female. The figure also displays the counterfactual distribution and excess mass, computed as described in Sect. 4. When estimating the counterfactual, a bunching window of 4 bins is excluded on each side of the kink

in occupation $i$ and industry $j$ is female. Basically, this exercise assigns more weight to males who work in female-dominated occupation-industry combinations. Figure 7 shows the corresponding result from the reweighting. I find the bunching among male wage earners after the reweighting to be much more pronounced, with the excess mass increasing from 0.24 to 0.37 , now being statistically significant. This rise in male bunching closes more than half of the gap in observed excess masses between men and women. Thus, some of the observed differences in bunching between men and women seem to be driven by occupational and industry choices. Previous research on the gender pay gap has shown that women tend to sort themselves into industries with more flexible employment arrangements (see, e.g., Goldin 2014). Since tax bunching requires a certain degree of flexibility in work hours and labor supply, sorting into more flexible industries may be one of the forces behind the larger bunching response of women. Interestingly, I find the differing bunching responses between men and women especially in gross earnings. In contrast, the increase in bunching after accounting for deductions is very similar for both groups, roughly around $50 \%$. This suggests that the differences in bunching between men and women are not driven by a differential use of deductions but rather by gross earnings responses.

\subsection{Self-employed}

In the following I examine whether self-employed taxpayers make similar use of deductions to target the first tax kink. As described in Sect. 3.1, the data of selfemployed taxpayers only provide information on two income measures, namely gross income (= business revenue minus business expenses) and taxable income (= gross 
income minus all other deductions such as personal expenses). ${ }^{25}$ Since business revenue and business expenses are usually less subject to third-party verification, they can more easily be manipulated by the taxpayer. Hence, I may expect self-employed taxpayers to target the kink already with their gross income, which they can control much more than wage earners.

Panel A of Fig. 8 plots gross income reported by self-employed taxpayers from 2005 to 2011 . There is an extremely clear spike at the first kink point, with an estimated excess mass of taxpayers of around 1.05, being highly statistically significant. Panel B displays the distribution of taxable income of the self-employed. I find again very sharp bunching, with the excess mass increasing slightly to 1.20 . Overall, the bunching of self-employed is much more pronounced compared to wage earners, for which I found an excess mass of 0.60 for 2005-2011 (see Fig. 2). Interestingly, much of the bunching response of the self-employed is already present when looking at gross income, in line with the expectation that gross income can be more easily controlled by self-employed taxpayers. In turn, the adjustment channel via other deductions such as personal expenses seems to be relatively less important for self-employed taxpayers than for wage earners. Specifically, relating the excess mass of taxable income to the excess mass of gross income gives a ratio of around 1.14, compared to a ratio of 1.5 for wage earners (see page 12). This suggests that access to different adjustment channels indeed corresponds with different adjustment behavior. This is also in line with earlier, mostly theoretical research on taxpayer substitution across different modes of tax avoidance/evasion (see, e.g., Martinez-Vazquez and Rider 2005). Having said this, the evidence presented here should be seen as rather informative but not conclusive. Unfortunately, the data at hand are not rich enough to dive deeper into the behavioral responses of self-employed taxpayers. For instance, it does not provide detailed balance sheet information, which would allow analysis of whether self-employed taxpayers respond mostly via (reported) business revenue or via business expenses (see Bachas and Soto (2015) for related evidence using firm tax data). Having access to more detailed tax return data to study the differential use of certain deduction line items could shed additional light on the mechanisms behind the responsiveness of taxpayers.

\section{Conclusion and discussion}

This study aims to uncover earnings supply and deduction responses of wage earners to a salient kink point in the Austrian tax schedule, contributing to the literature on the effect of taxes on different tax adjustment channels. Exploiting the introduction of a very large first tax bracket for identification, I document gross earnings and significantly sharper taxable earnings responses. I observe wage earners targeting the kink with their gross earnings as well as deductions and find the latter to be very responsive when taxpayers cross into the first tax bracket with their gross earnings.

\footnotetext{
25 Importantly, other deductions such as personal expenses comprise the same items as for wage earners, e.g., premiums for personal insurance (health, life insurance), charitable giving, child care costs, tax consultant fees or mortgage interest payments for private housing. As for wage earners, I do not observe the single line items, but the total sum taxpayers deduct as personal expenses.
} 


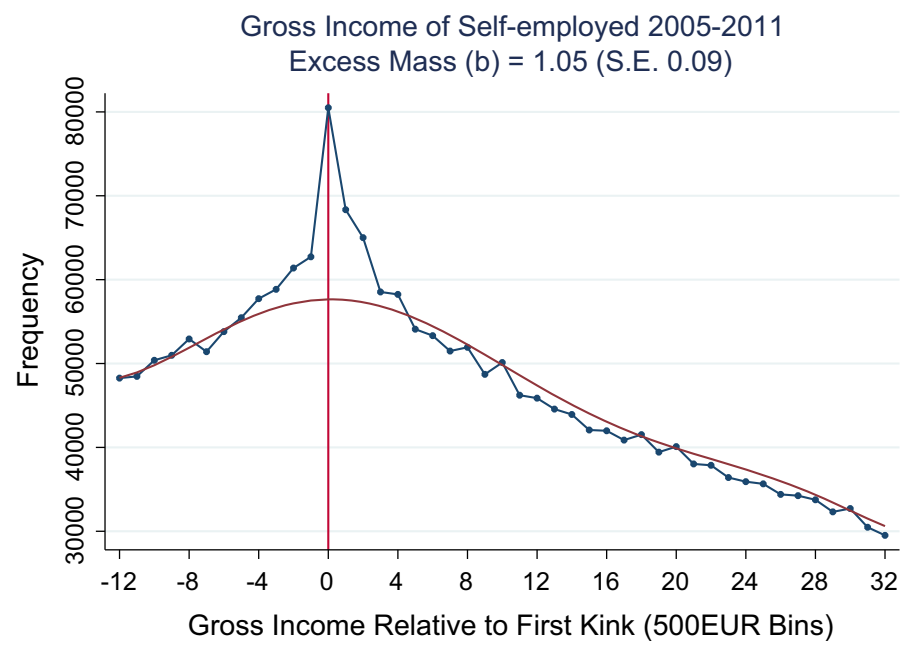

Panel A

Taxable Income of Self-employed 2005-2011

Excess Mass $(b)=1.20$ (S.E. 0.07)

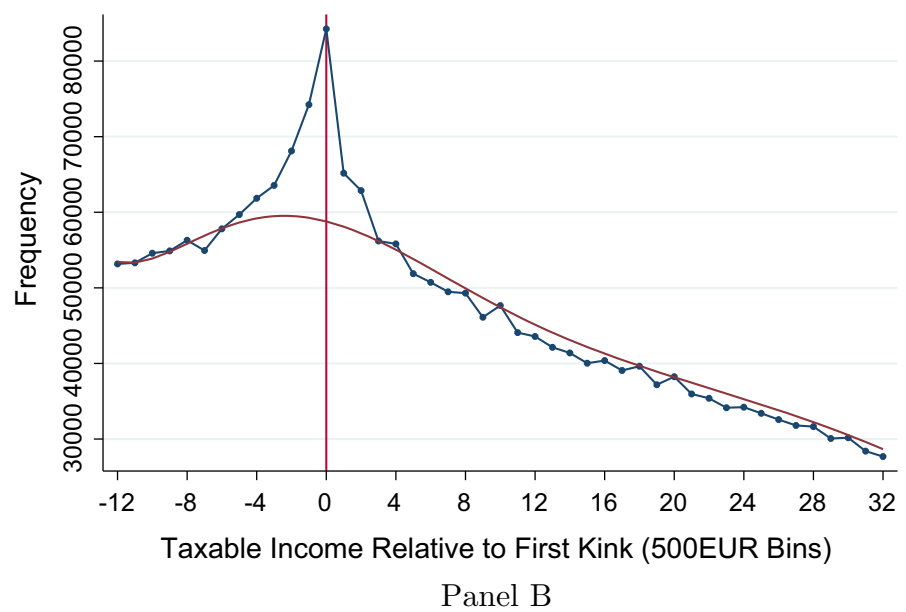

Fig. 8 Gross income versus taxable income distribution of self-employed (2005-2011). Notes: Panel A Gross income (= business revenue minus business expenses) of self-employed taxpayers from 2005 to 2011. Panel B Taxable income (= gross income minus other deductions such as personal expenses) of all selfemployed taxpayers from 2005 to 2011. The series shown in dots is a histogram of gross income (or taxable income, respectively) relative to the first tax bracket. Both panels display the counterfactual distribution and excess mass, computed as described in Sect. 4

Furthermore, I observe that adjustment behavior varies with the access to different tax adjustment channels, suggesting that access to one channel affects the use of other channels.

Tests restricting the analysis to larger firms indicate that the observed gross earnings response is not primarily driven by wage underreporting but rather constitutes a real 
earnings supply response. This points at the existence of adverse incentives to work, created by the income tax schedule. For claimed deductions, it is more difficult to pin down real versus avoidance/evasion responses, since they are comprised of several different deduction items (and data on specific line items is not available). Paetzold and Winner (2016) and Frimmel et al. (2017) suggest that in the case of the commuter tax break, at least some of the observed deduction responses are due to evasion. Unfortunately, the data at hand do not allow to investigation of the degree of evasion on other deduction items. There exists also no aggregate evidence which could help to gauge the extent of overreported deductions in Austria. However, my findings show that even for taxpayers with only limited possibilities to shelter taxable income (in this case wage earners), deduction responses represent an important channel to reduce tax liabilities.

Recent theoretical work argues that the elasticity of taxable income is not sufficient for welfare analysis if (i) deductions are responsive to tax rate changes and if (ii) deductions generate externalities (see Doerrenberg et al. 2016). While my paper presents evidence on the first condition, the question whether and to what extent deductions generate externalities is yet to be answered. Chetty (2009) proposes a model where losses to overall welfare depend on whether adjustments to taxable income incur transfer versus real resource costs. Hence, future research may examine whether taxpayers are more responsive via deduction items that are associated with resource costs rather than with transfers. This would help researchers as well as policymakers to decide which income measure to use (taxable income vs. gross income) when evaluating the impact of tax reforms.

Acknowledgements Open access funding provided by Austrian Science Fund (FWF). Parts of the paper were written during a research visit at the UC Berkeley Center for Equitable Growth. I am grateful for the center's hospitality and are especially to Emmanuel Saez for research guidance and invaluable advice. I would like to thank Pierre Bachas, Spencer Bastani, Alex Gelber, Wojciech Kopczuk, Tuomas Kosonen, Camille Landais, Attila Lindner, Simon Loretz, Tuomas Matikka, Andreas Peichl, Yotam Shem-Tov, Sebastian Siegloch, Joel Slemrod, Christian Traxler and numerous seminar participants at Berkeley, CESifo Munich, Innsbruck, the NTA Annual Conference 2015, WIFO Vienna and ZEW Mannheim for helpful comments and discussions. Financial support from the Austrian Science Fund FWF (Project No. J3719-G27) and the University of Salzburg is gratefully acknowledged.

Open Access This article is distributed under the terms of the Creative Commons Attribution 4.0 International License (http://creativecommons.org/licenses/by/4.0/), which permits unrestricted use, distribution, and reproduction in any medium, provided you give appropriate credit to the original author(s) and the source, provide a link to the Creative Commons license, and indicate if changes were made.

\section{Appendix A}

\section{Appendix A.1: Aggregate versus individual bunching}

In the following I present evidence against the notion that the bunching I observe is driven by aggregate bunching (i.e., bunching created by firms/unions via tailored wage-hour packages) instead of individual bunching. For this purpose, I provide two tests aimed at uncovering such aggregate bunching in the data. 
Gross Wage Earnings of Employees with Self-Employed Income

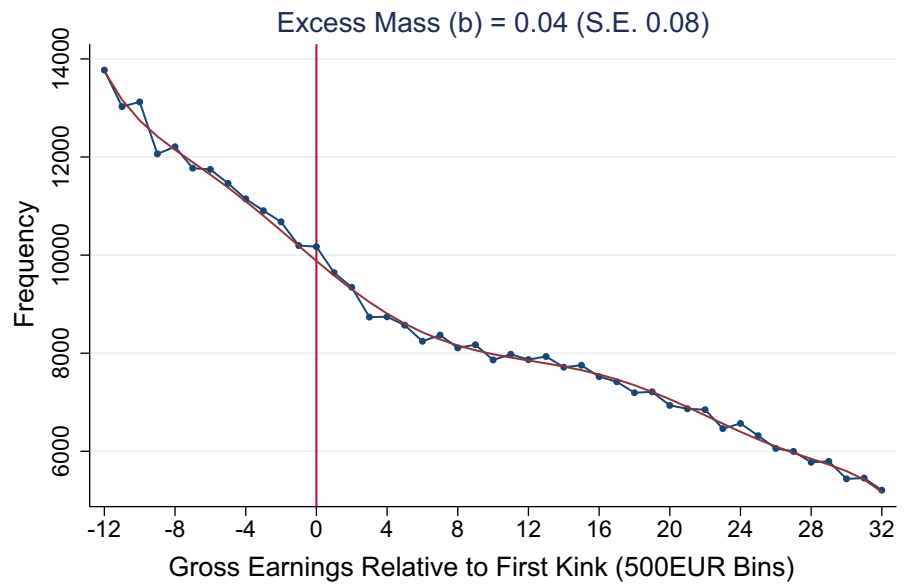

Fig. 9 Gross earnings distribution of wage earners with self-employed income. Notes: The figure shows the distribution of gross wage earnings for employees with significant income from self-employment (defined as having self-employed income of more than 1000 EUR). The series shown in dots is a histogram of gross wage earnings relative to the first tax bracket. For estimating the counterfactual, a bunching window of 4 bins is excluded on each side of the kink

\section{Gross Earnings 2005-2011 (large Firms only)}

Excess Mass $(b)=0.34$ (S.E. 0.06$)$

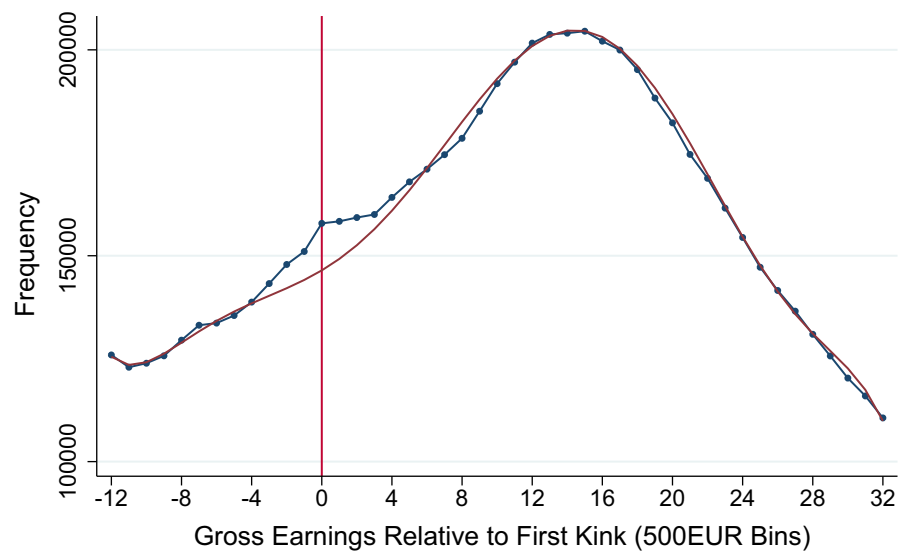

Fig. 10 Gross earnings distribution of wage earners working in large firms (> 250 employees). Notes: This Figure replicates Panel A of Fig. 2 for wage earners working at firms with more than 250 employees. When restricting the sample to individuals working at firms with more than 250 employees, the number of observations equals 9,717,045 (stemming from around 2.6 million unique wage earners)

To begin with, I interpret the pattern I document in Fig. 3 as suggestive evidence against the presence of aggregate bunching. The pattern in my data is fundamentally different from the findings of aggregate bunching presented by Chetty et al. (2011), who observe bunching at the kink even among workers who have no incentive to locate there. Specifically, they observe taxpayers bunching at the statutory (=zero deduction) 


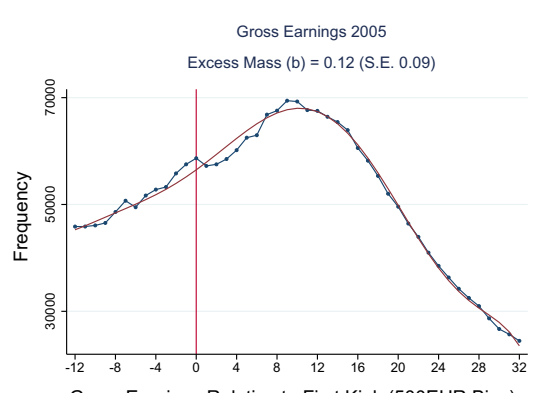

Gross Earnings Relative to First Kink (500EUR Bins)

Panel A

Gross Earnings 2007

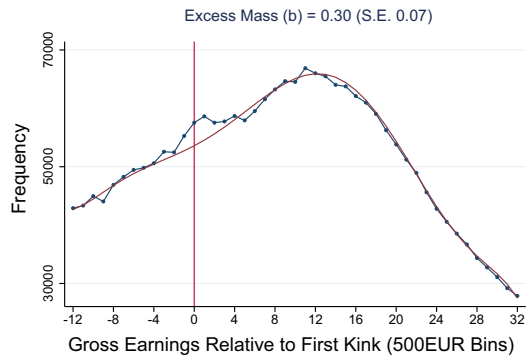

Panel C

Gross Earnings 2009

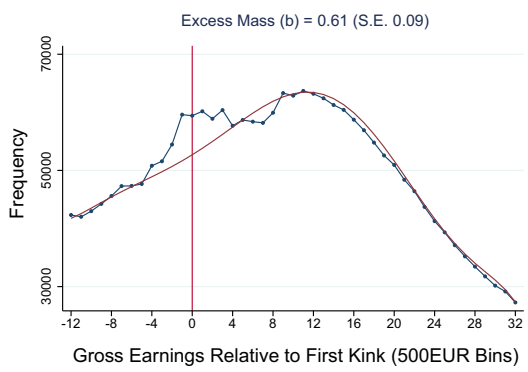

Panel E

Gross Earnings 2011

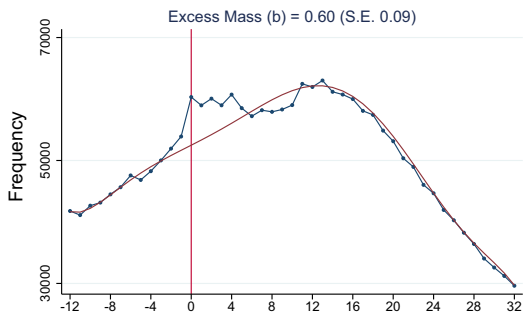

Gross Earnings Relative to First Kink (500EUR Bins)

Panel G

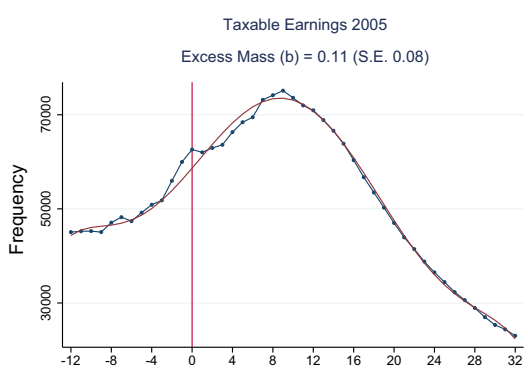

Taxable Earnings Relative to First Kink (500EUR Bins)

Panel B

Taxable Earnings 2007

Excess Mass $(b)=0.47$ (S.E. 0.06 )

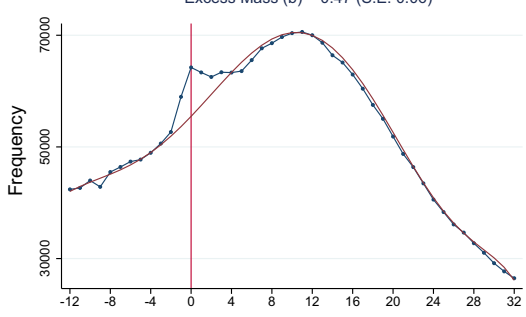

Taxable Earnings Relative to First Kink (500EUR Bins)

Panel D

Taxable Earnings 2009

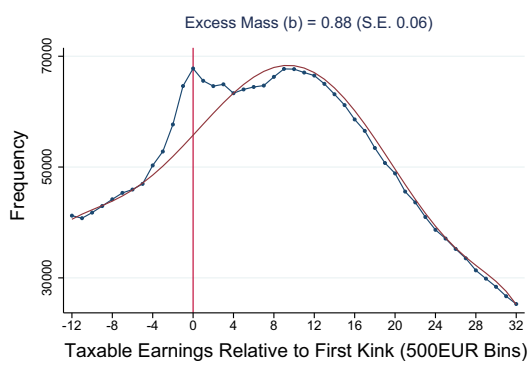

Panel F

Taxable Earnings 2011

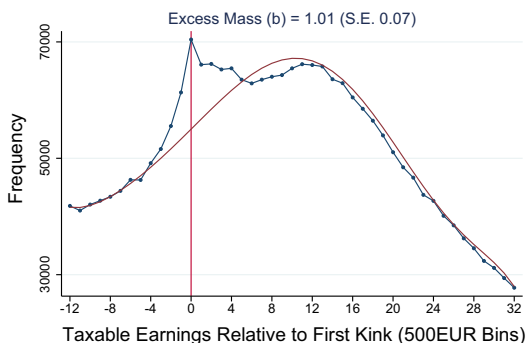

Panel H

Fig. 11 Increase in bunching over time. Notes: These figures plot the empirical distributions of gross earnings (left column) as well as taxable earnings (right column) for every other year from 2005 to 2011 . The solid vertical lines mark the first kink point in the respective year. Each panel also displays the counterfactual distribution and excess mass, computed as described in Sect. 4. When estimating the counterfactual, a bunching window of 4 bins is excluded on each side of the kink 
cutoff point despite claiming large deductions (see Fig. VII of their paper). They label this the 'signature of aggregate bunching.' Their result is in sharp contrast to my findings in Fig. 3 which shows that taxpayers are much more concentrated at the corresponding gross earnings level where, given the level of deductions they claim, their marginal tax rate changes.

Second, I execute a test put forward by Best (2014). To be more precise, I examine bunching of gross wage earnings of employees with some self-employed income. The idea is that if aggregate bunching is at play, the aggregate distribution of jobs should locate even those employees at the kink with their gross wage earnings despite having no incentive to bunch there (since they are taxed not only by their gross wage earnings but by their total income, i.e., the sum of wage earnings and self-employed income). Figure 9 focuses on a subset of workers with income from self-employment and plots the distribution of their gross wage earnings. I do not find any evidence of bunching of gross wage earnings for those employees. This is in contrast to Best (2014), who uses sharp bunching of salaries for workers with additional non-salary earnings to demonstrate that firms are placing salary-hours offers around the kinks of the tax schedule (Figs. 10, 11).

\section{Appendix A.2: Deduction targeting by wage earners}

Figure 12 further illustrates targeting behavior by wage earners. This time, I normalize the claimed deductions for each individual wage earner so that zero would be the exact

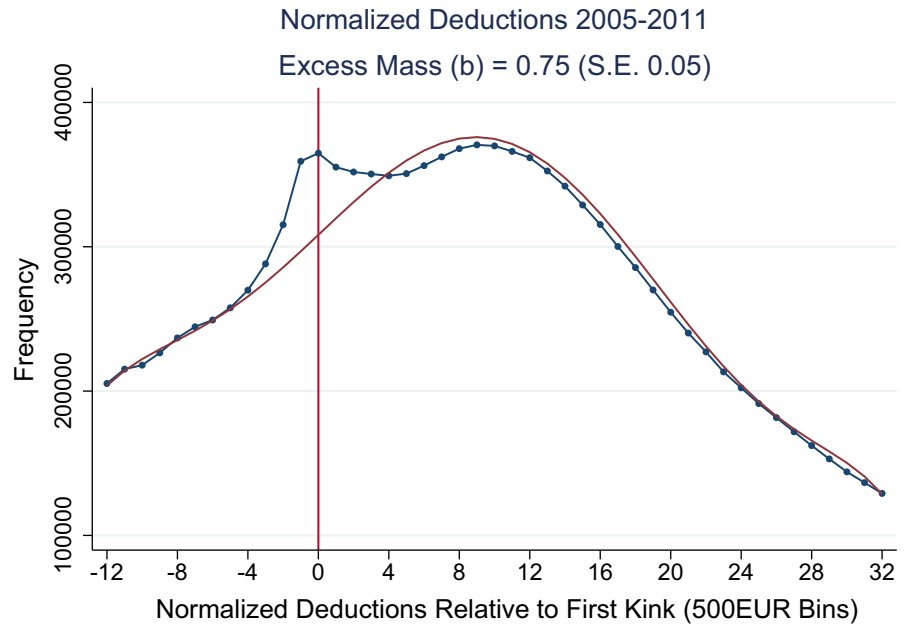

Fig. 12 Distribution of normalized deductions (2005-2011). Notes: This figure plots the distribution of normalized deductions 2005-2011. Actual claimed deductions are normalized so that zero is the exact amount a taxpayer needs to target the kink with his/her taxable earnings (for given gross income). Hence, the new running variable ('normalized deductions') is the difference between gross earnings and claimed deductions. The series shown in dots is a histogram of normalized deductions relative to the kink. Each point shows the number of observations in a 500 EUR wide bin of normalized deductions. The solid line beneath the empirical distribution is a seventh-degree polynomial fitted to the empirical distribution excluding a bunching window of 4 bins 
amount a taxpayer needs to target the kink with his/her taxable earnings (for given gross earnings). Thus, the new running variable ('normalized deductions') captures the difference between gross earnings and claimed deductions, which takes a value of zero when the taxpayer deducts exactly the amount needed to bunch at the kink. I again put taxpayers in 500 EUR wide bins of this new running variable and use a bunching window of 4 bins. Figure 4 depicts a large spike of normalized deductions at the kink point. It shows that taxpayers tend to deduct exactly the amount needed in order to bunch at the kink.

\section{Appendix A.3: Robustness of results}

Table 4 shows a series of robustness tests regarding the choice of bin width, polynomial order and bunching window $[-R, R]$. Panel A of Table 4 displays my baseline choice. In Panel B, I vary the bin width, using bins of 250 EUR and 350 EUR, respectively. ${ }^{26}$ Panel C shows different choices of the polynomial degree. In Panel D, I vary the size of the bunching window. Overall, the sensitivity analyses show similar patterns to the baseline. While the size of the excess mass sometimes varies, I find that bunching remains statistically significant in all cases. In sum, I find in all cases that the additional mass of wage earners at the kink is higher after accounting for all deductions, with the ratio of taxable earnings to gross earnings ranging from 1.3 to 1.8 (depicted in column 'Ratio TE/GE').

\footnotetext{
26 Please note that in order to keep the bunching window identical to the baseline, I need to exclude more bins, e.g., $[-8,8]$ bins when using a bin width of 250 EUR.
} 


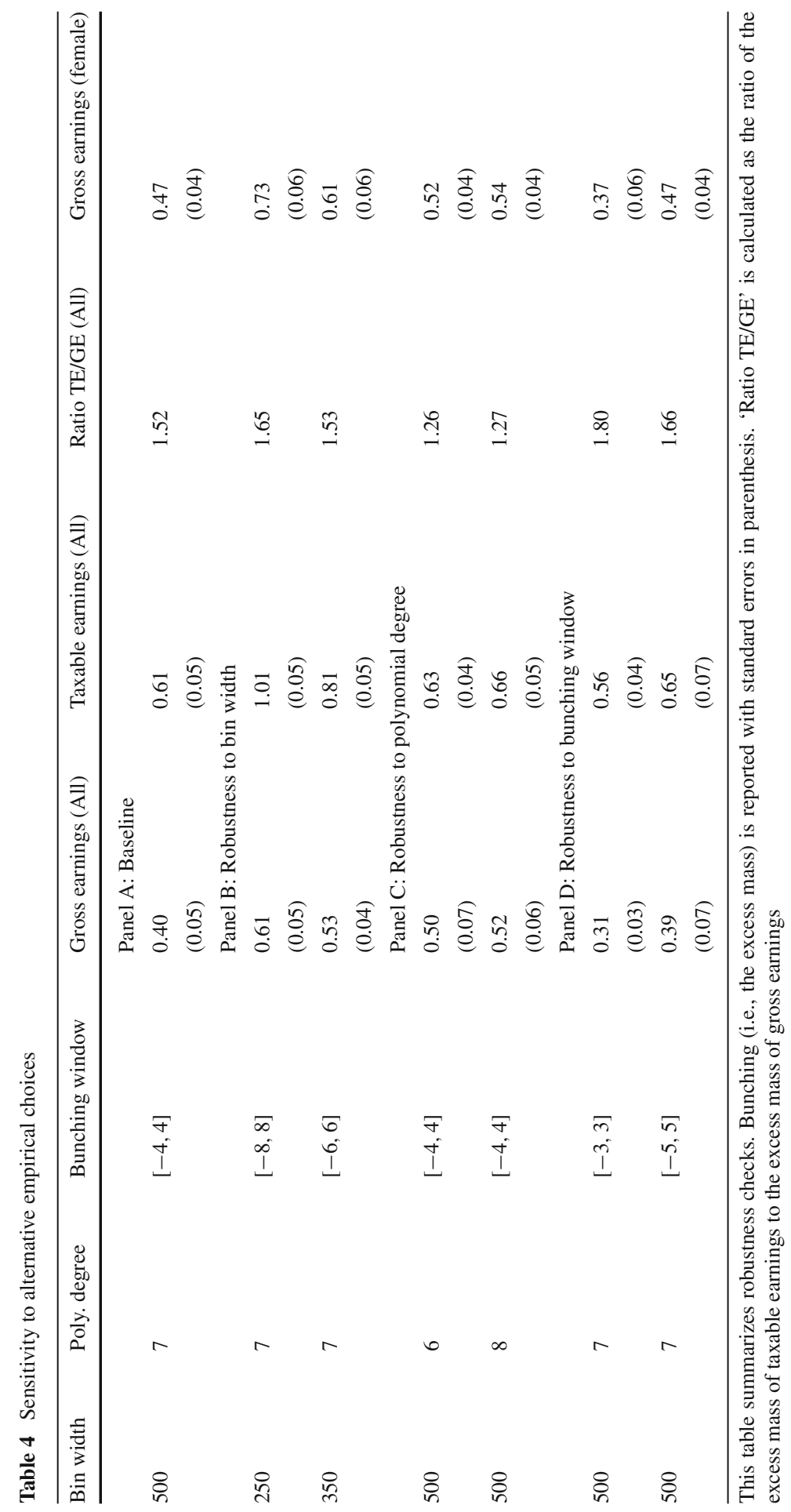




\section{Appendix A.4: Bunching persistence}

In the following I examine whether the deduction behavior documented in the main text translates into bunching persistence over time. Therefore, Fig. 13 plots the persistence in gross earnings versus persistence in taxable earnings. Panel A (B) puts taxpayers into 1000 EUR wide bins of gross earnings (taxable earnings) and plots the fraction

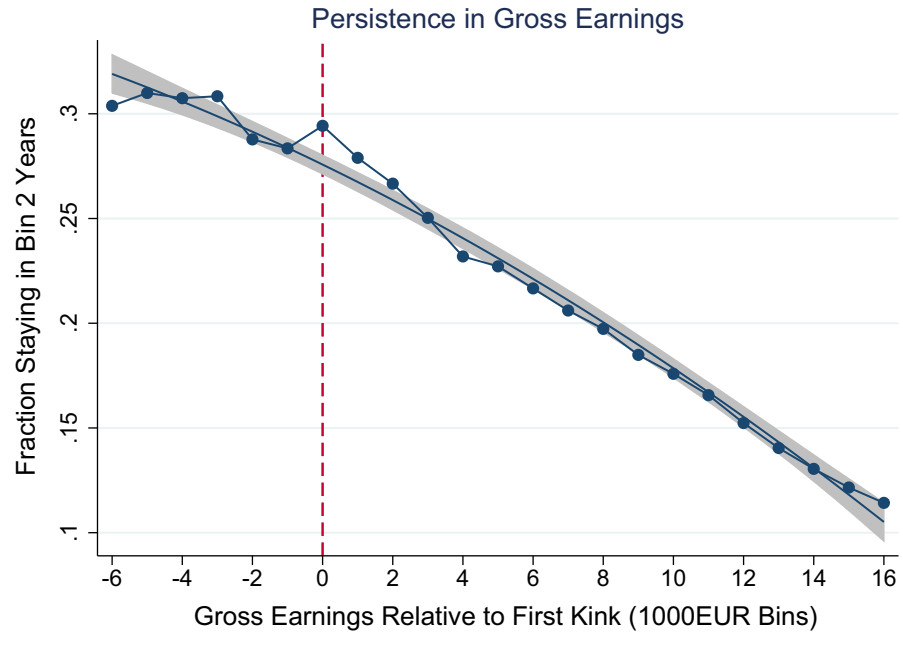

Panel A

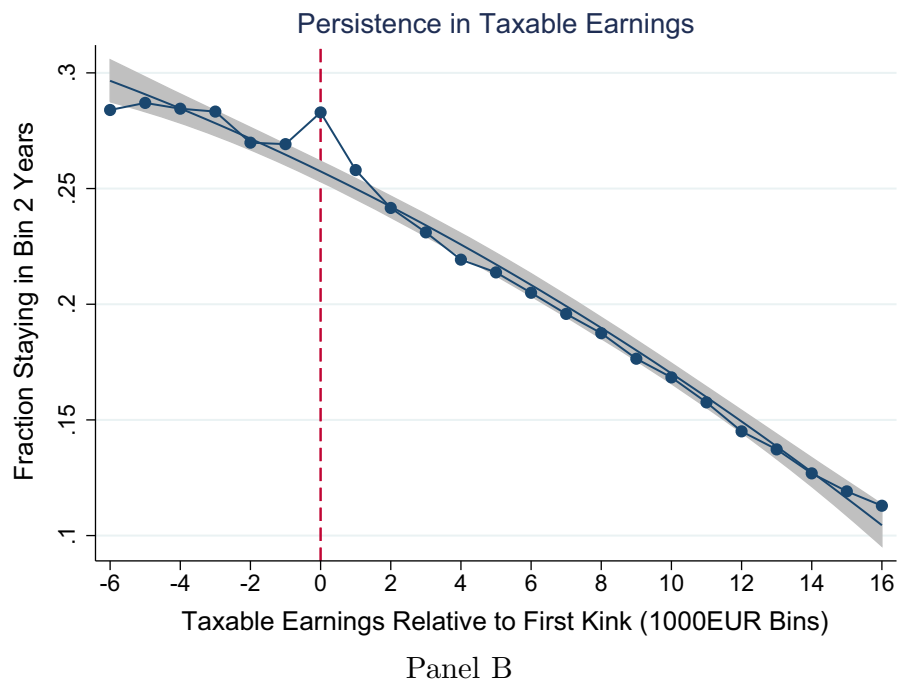

Fig. 13 Persistence in gross earnings versus taxable earnings. Notes: This figure shows persistence in gross earnings versus taxable earnings over time. Panel A (B) plots the fraction of individuals who remain in the same gross earnings (taxable earnings) bin after two years. The solid blue curves are quadratic fits of the respective bin averages. The solid vertical line displays the cutoff point of the first kink 

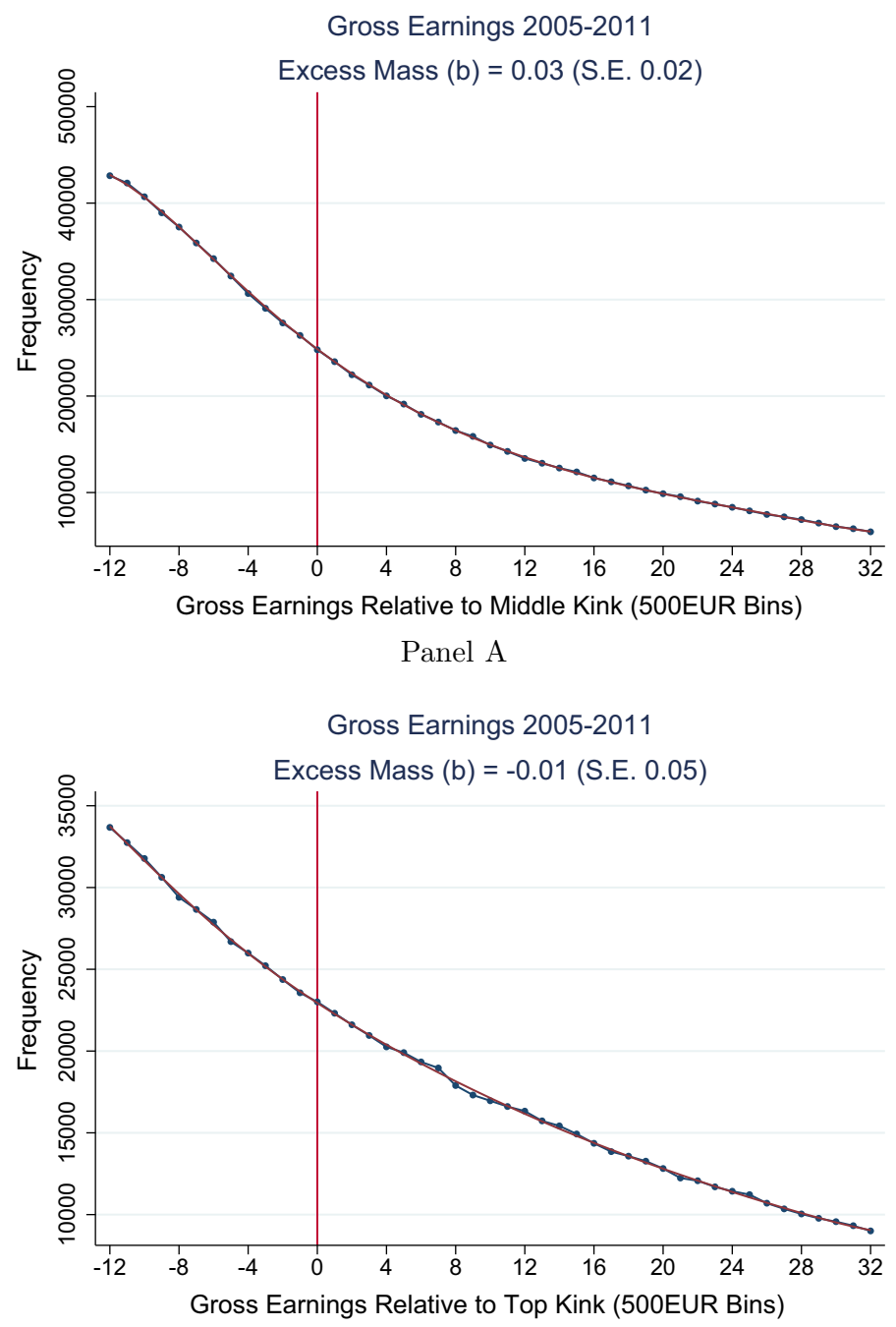

Panel B

Fig. 14 Distribution of wage earnings around middle and top kink. Notes: Panel A (B) plots the gross earnings distribution around the middle (top) kink of the Austrian income tax schedule. The series shown in dots is a histogram of gross earnings relative to the middle (top) tax kink. Each point shows the number of observations in a 500 EUR wide bin. The solid line beneath the empirical distribution is a seventh-degree polynomial fitted to the empirical distribution excluding a bunching window of 4 bins on each side of the respective kink

of individuals who remain in the same bin after two years. Again, I add a quadratic polynomial of the bin averages to approximate the counterfactual probability to stay in a given bin. For both earnings measures, I find the probability of staying in the same bin to decline smoothly with earnings but observe a deviation from this trend 
exactly around the kink point. Mirroring my results of the main text, I find a sharper and bigger deviation for taxable earnings in Fig. $14 .^{27}$

\section{References}

Almunia, M., \& Lopez-Rodriguez D. (2015). Heterogeneous responses to effective tax enforcement: Evidence from Spanish firms. Banco de España, Working Paper No. 1419.

Alstadsaeter, A., Johannesen, N., \& Zucman. G. (2017). Tax evasion and inequality. Working Paper.

Bachas, P., \& Soto. M. (2015). Not(ch) your average tax system: Corporate taxation under weak enforcement. Working Paper.

Bastani, S., \& Selin, H. (2014). Bunching and non-bunching at kink points of the Swedish tax schedule. Journal of Public Economics, 109, 36-49.

Best, M. (2014). The role of firms in workers earnings responses to taxes: Evidence From Pakistan. Working Paper, London School of Economics.

Chetty, R. (2009). Is the taxable income elasticity sufficient to calculate deadweight loss? The implications of evasion and avoidance. American Economic Journal: Economic Policy, 1, 31-52.

Chetty, R. (2012). Bounds on elasticities with optimization frictions: A synthesis of micro and macro evidence on labor supply. Econometrica, 80, 969-1018.

Chetty, R., Friedman, J. N., Olsen, T., \& Pistaferri, L. (2011). Adjustment costs, firm responses, and micro vs. macro labor supply elasticities: Evidence from Danish tax records. Quarterly Journal of Economics, 126, 749-804.

Chetty, R., Friedman, J. N., \& Saez, E. (2013). Using differences in knowledge across neighborhoods to uncover the impacts of the EITC on earnings. American Economic Review, 103, 2683-2721.

Duquette, N. (2016). Do tax incentives affect charitable contributions? Evidence from public charities. Journal of Public Economics, 137, 51-69.

Doerrenberg, P., \& Duncan, D. (2014). Experimental evidence on the relationship between tax evasion opportunities and labor supply. European Economic Review, 68, 48-70.

Doerrenberg, P., Peichl, A., \& Siegloch, S. (2016). The elasticity of taxable income in the presence of deduction possibilities. Journal of Public Economics, 151, 41-55.

Engström, P., Nordblom, K., Ohlsson, H., \& Persson, A. (2015). Tax compliance and loss aversion. American Economic Journal: Economic Policy, 7(4), 132-164.

Fack, G., \& Landais, C. (2010). Are tax incentives for charitable giving efficient? Evidence from France. American Economic Journal: Economic Policy, 2(2), 117-141.

Frimmel, W., Halla, M., \& Paetzold, J. (2017). The intergenerational causal effect of tax evasion: Evidence from a commuter tax allowance in Austria. University of Innsbruck Working Paper 2017-01.

Gelber, A., Jones, D., \& Sacks, D. (2016). Earnings adjustment frictions: Evidence from the social security earnings test. GSPP Working Paper.

Goldin, C. (2014). A grand gender convergence: Its last chapter. American Economic Review, 104(4), 1091-1119.

Harju, J., \& Matikka, T. (2016). The elasticity of taxable income and income shifting between tax bases: What is 'real' and what is not? International Tax and Public Finance, 23(4), 640-669.

Klepper, S., \& Nagin, D. (1989). The anatomy of tax evasion. Journal of Law, Economics and Organization, 5(1), 1-24.

Kleven, H. (2016). Bunching. Annual Review of Economics, 8, 435-464.

Kleven, H., Knudsen, M., Kreiner, C. T., Pedersen, S., \& Saez, E. (2011). Unwilling or unable to cheat? Evidence from a tax audit experiment in Denmark. Econometrica, 79, 651-692.

Kleven, H., \& Schultz, E. (2014). Estimating taxable income responses using Danish tax reforms. American Economic Journal: Economic Policy, 6(4), 271-301.

Kleven, H., \& Waseem, M. (2013). Using notches to uncover optimization frictions and structural elasticities: Theory and evidence from Pakistan. Quarterly Journal of Economics, 128, 669-723.

\footnotetext{
27 It is important to note that the kink is not adjusted for inflation. Hence, staying at the kink over time means to either accept real earnings losses or to increase deductions. Furthermore, I again do not select on filing a tax return but use the entire population in my sample.
} 
Kosonen, T., \& Matikka, T. (2016). The accuracy of bunching method under optimization frictions: Students' constraints. CESifo Public Sector Area Conference Paper.

Kreiner, C. T., Leth-Petersen, S., \& Skov, P. E. (2014). Year-end tax planning of top management: Evidence from high-frequency payroll data. American Economic Review: Papers and Proceedings, 103, 154158.

Kumler, T., Verhoogen, E., \& Frias, J. A. (2015). Enlisting employees in improving payroll-tax compliance: Evidence from Mexico. NBER Working Paper No. 19385.

LaLumia, S., Sallee, J., \& Turner, N. (2015). New evidence on taxes and the timing of birth. American Economic Journal: Economic Policy, 7(2), 258-293.

Maire, D., \& Schjerning, B. (2013). Tax bunching income shifting and self-employment. Journal of Public Economics, 107, 1-18.

Martinez-Vazquez, J., \& Rider, M. (2005). Multiple modes of tax evasion: Theory and evidence. National Tax Journal, 58(1), 51-76.

Marx, B. (2015). Dynamic bunching estimation and the cost of regulatory hurdles for charities. Working Paper.

Matikka, T. (2016). The elasticity of taxable income: Evidence from changes in municipal income tax rates in Finland. Scandinavian Journal of Economics (forthcoming).

Mortenson, J., \& Whitten, A. (2016). Bunching to maximize tax credits: Evidence from kinks in the U.S. Tax Schedule. Working Paper.

Paetzold, J., \& Winner, H. (2016). Taking the high road? Compliance with commuter tax allowances and the role of evasion spillovers. Journal of Public Economics, 143, 1-14.

Rees-Jones, A. (2018). Loss aversion motivates tax sheltering: Evidence from U.S. Tax Returns. The Review of Economic Studies, 85(2), 1251-1278.

Saez, E. (2010). Do taxpayers bunch at kink points? American Economic Journal: Economic Policy, 2, 180-212.

Saez, E., Slemrod, J., \& Giertz, S. H. (2012). The elasticity of taxable income with respect to marginal tax rates: A critical review. Journal of Economic Literature, 50(1), 3-50.

Scharf, K., \& Smith, S. (2015). The price elasticity of charitable giving: Does the form of tax relief matter? International Tax and Public Finance, 22, 330-352.

Tazhitdinova, A. (2015). Adjust Me if I Can't: The effect of firm incentives on labor supply responses to taxes. Working Paper.

Weber, C. (2014). Toward obtaining a consistent estimate of the elasticity of taxable income using differencein-differences. European Journal of Public Economics, 117, 90-103. 